\title{
Global Warming and Extreme Events: Rethinking the Timing and Intensity of Environmental Policy
}

\author{
$\mathrm{Yu}-\mathrm{Fu}$ Chen \\ Michael Funke
}

\author{
CESIFO WORKING PAPER NO. 3139 \\ CATEGORY 9: RESOURCE AND ENVIRONMENT ECONOMICS \\ JULY 2010
}
An electronic version of the paper may be downloaded
- from the SSRN website:
- from the RePEc website:
- from the CESifo website:
www.SSRN.com
Www.RePEc.org
www.CESifo-group.org/wp




\title{
Global Warming and Extreme Events: Rethinking the Timing and Intensity of Environmental Policy
}

\begin{abstract}
The possibility of low-probability extreme events has reignited the debate over the optimal intensity and timing of climate policy. In this paper we therefore contribute to the literature by assessing the implications of low-probability extreme events on environmental policy in a continuous-time real options model with "tail risk". In a nutshell, our results indicate the importance of tail risk and call for foresighted pre-emptive climate policies.
\end{abstract}

JEL-Code: D81, Q54, Q58.

Keywords: climate policy, extreme events, real options, Levy process.

Yu-Fu Chen

University of Dundee

Economic Studies

Dundee DD1 4HN

United Kingdom

y.f.chen@dundee.ac.uk
Michael Funke

Hamburg University

Department of Economics

Von-Melle-Park 5

20146 Hamburg

Germany

funke@econ.uni-hamburg.de

Dundee \& Hamburg, June 2010

Financial support from the "Integrated Climate System Analysis and Prediction (CliSAP)" cluster of excellence of Hamburg University is gratefully acknowledged. Comments and suggestions from Hermann Held (Potsdam Institute for Climate Impact Research) are gratefully acknowledged. The usual disclainer applies. 


\section{Introduction}

The term extreme events refers to infrequent weather and natural events that depart heavily from the average. Scientists cannot state with confidence that today's extreme events are the first signs of climate change arising from greenhouse gas (GHG) emissions. Nevertheless, monitoring and studying extreme events, and learning how to cope with them, must be a priority. Global climate change could well affect the frequency, magnitude and location of extreme events. Extreme weather events that may be considered here include droughts (due to increased evaporation and reduced precipitation), river floods (due to increased precipitation), landslides (due to increased precipitation), Storms, cyclones and tornadoes (due to changing heat transport patterns and increased land-ocean temperature differential), and ocean and coastal surges and related flooding (due to storms and sea level rise). Any shift in mean climate will almost inevitably boost the frequency of these extreme events and some of these changes are already occuring and traditional diversification strategies may fail. Extreme climate events are different from other shocks because their impacts are persistent for many years or even permanent. Therefore extreme event research can be classified as an interdisciplinary cross-cutting issue.

The occurrence of an extreme event, however, does not automatically imply prolonged impacts upon economies. Apart from the obvious situation where an event occurs in an uninhabited area, impacts will vary depending not only on place of occurrence but also with spatial and temporal dimensions and the population and wealth at risk. It is, however, likely that extreme events will have an increasing effect on human well-being in future decades. ${ }^{1}$ Because the most affected countries in the tropics are poor, those most likely to be affected will be least able to adapt. On the other hand, the colder parts in the northern hemisphere may benefit from climate change, but they too face perils. Due to these facts, critics of policies to reduce GHG emissions vigorously question whether policymakers should address these issues now, given that the monitoring of extreme event impacts is fraught with difficulties. These difficulties arise both from the variety of physical characteristics of extreme events as well as from the variety of countries. ${ }^{2}$

The layout of the paper is as follows. Section 2 offers context on the broader extreme event risks involved. In section 3 we develop a continuous-time real option model of climate policy with "tail risk” addressing the complexities of climate change interactions and their challenging policy impacts. A hallmark of the real options model with "tail risk" presented below is a delicate choice of assumptions to capture the essence while retaining tractability. Section 4 contains an in-depth

\footnotetext{
${ }^{1}$ Societies have witnessed this fat-tail phenomenon in the last decade with the September 11 terrorist attack and financial losses during the financial crisis of 2008-2009.

${ }^{2}$ The recently published fourth assessment report of the Intergovernmental Panel on Climate Change (IPCC) illustrates a curious aspect of the science of climate change. Studying the climate system reveals new, little understood, mechanisms and feedback effects that may increase or decrease warming. So as understanding
} 
numerical analysis and interpretation of our results. The final section of the paper summarizes some key findings and draws out some brief policy implications. Technical details and derivations are outlined in appendices.

\section{Large Scale Extreme Events - A Global Assessment}

The link between global warming and extreme weather events is well-researched. The Intergovermental Panel on Climate Change (IPCC, 2007) among other leading scientific groups has indicated that global warming will cause an increase in the frequency and severity of extreme weather events and natural disasters. The Stern (2007) report argues that due to the fact that extent of damage resulting from storms increases exponentially (to the power of three or more) with wind speed, costs of extreme weather events are estimated to reach $0.5 \%-1.0 \%$ of global GDP annually by 2050. Webster et al. (2005) and Hoyos et al. (2006) have shown that the number, duration, and intensity of hurricanes are highly correlated with temperature. As a result, hurricanes will be more intense under warmer, high $\mathrm{CO}_{2}$ conditions than under present-day conditions.

First, it is useful to define extreme events. Several terms, such as extreme event, disaster, catastrophic event, among others have been used interchangeably in the literature. In this section we first concentrate upon meteorological disasters (storms), hydrological disasters (floods, landslides), and climatological disasters (droughts, wildfires, extreme temperatures). ${ }^{3}$ The data below are gathered from the Emergence Events Database (EM-DAT). ${ }^{4}$ For an extreme event to be entered into the EMDAT database, at least one of the following four criteria has to be satisfied: (i) Ten or more people reported killed, (ii) one hundred people reported affected, (iii) the issuing of a call for international assistance or (iv) the declaration of a state of emergency.

Figure 1 indicates the trends of disaster frequency by type between 1900 and 2008. All three types of disasters have barely changed until the 1960s. From this point on, however, their frequency began to rise. ${ }^{5}$ On average, 71 disasters per year have occurred during the 1970s. This number grew to 354 per year from 2000-2008. Parallel to that, economic damage caused by disasters has also been increasing.

grows, predictions become less, rather than more certain. Thus, the IPCC's range of predictions of the rise in the temperature by 2100 has increased from $1.4-5.8{ }^{\circ} \mathrm{C}$ in the 2001 report to $1.1 .-6.4{ }^{\circ} \mathrm{C}$ in the latest report.

${ }^{3}$ Conversely, we do not consider extreme events of geological origin like earthquakes and volcanic eruptions or biological disasters comprising of epidemics.

${ }^{4}$ The EM-DAT database is compiled by the Centre for Research on the Epidemiology of Disasters (CRED) of the Université Catholique de Louvain (see http://www.emdat.be/). Another data source for disaster data is the NATCAT database by Munich Re (see http://www.munichre.com/en/ts/geo_risks/natcatservice/default.aspx).

${ }^{5}$ When interpreting the numbers, one has to take into account that a host of factors unrelated to global warming may have contributed to the enormous rise in reported disasters. Over the last decades, the development of telecommunication and media has played a non-negligible role in the number of disasters reported internationally. The increase in the number of events until the mid 1990s can probably explained by better reporting and registering of disasters. In contrast, the most recent data are probably less biased and reflect a real change in the numbers observed. Nonetheless, one has to be careful when interpreting the disaster data because of simultaneous trends in population growth, urbanisation and the like. 
Figure 1: Number of Disasters Registered in EM-DAT

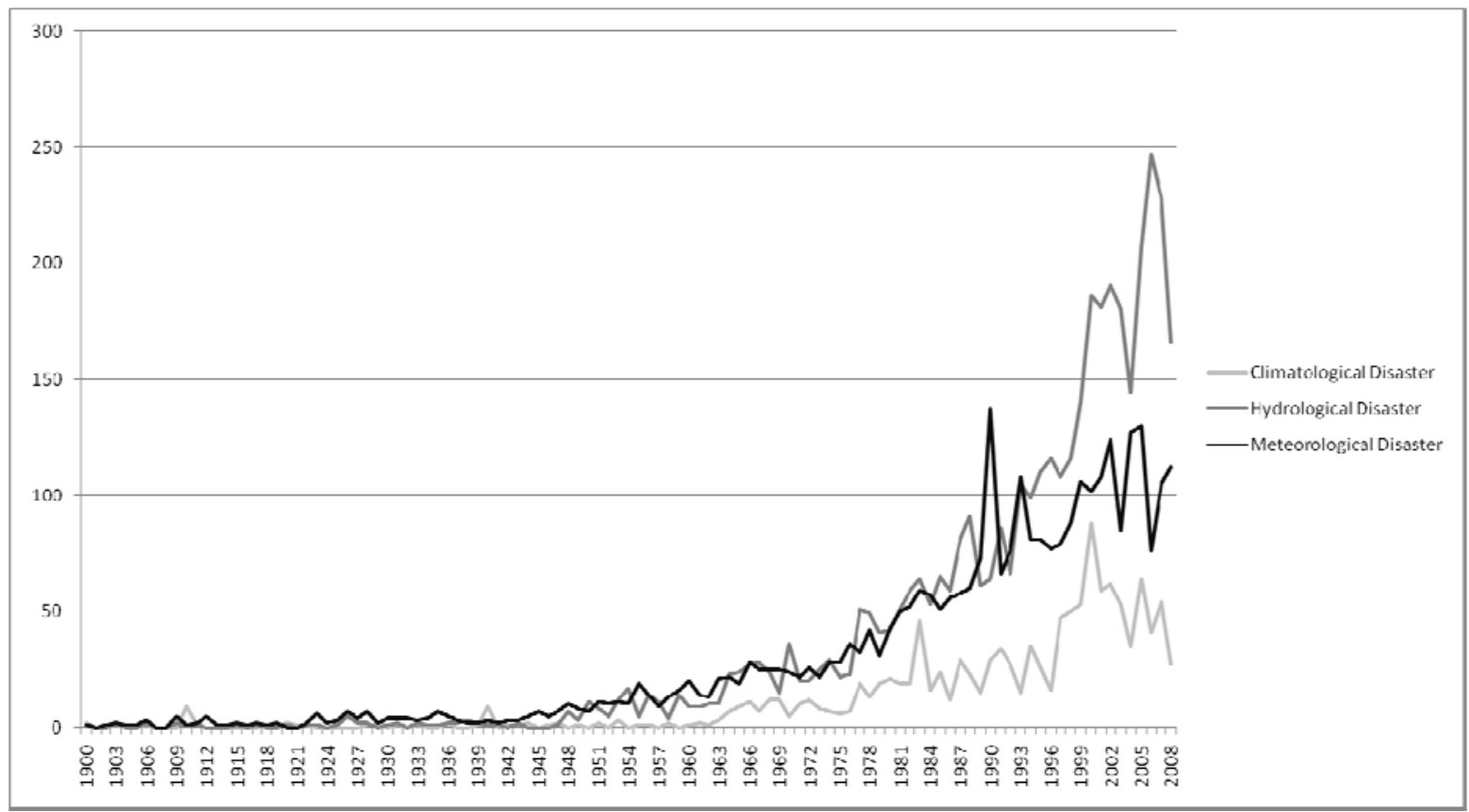

Figure 2 illustrates the estimated economic damage costs of these events which have increased noticeably. Damages have averaged US \$ 75 billion per year since 2000. The statistics presented above imply that extreme events are already a major issue.

Figure 2: Estimated Economic Damages by Disaster (US \$ billion)

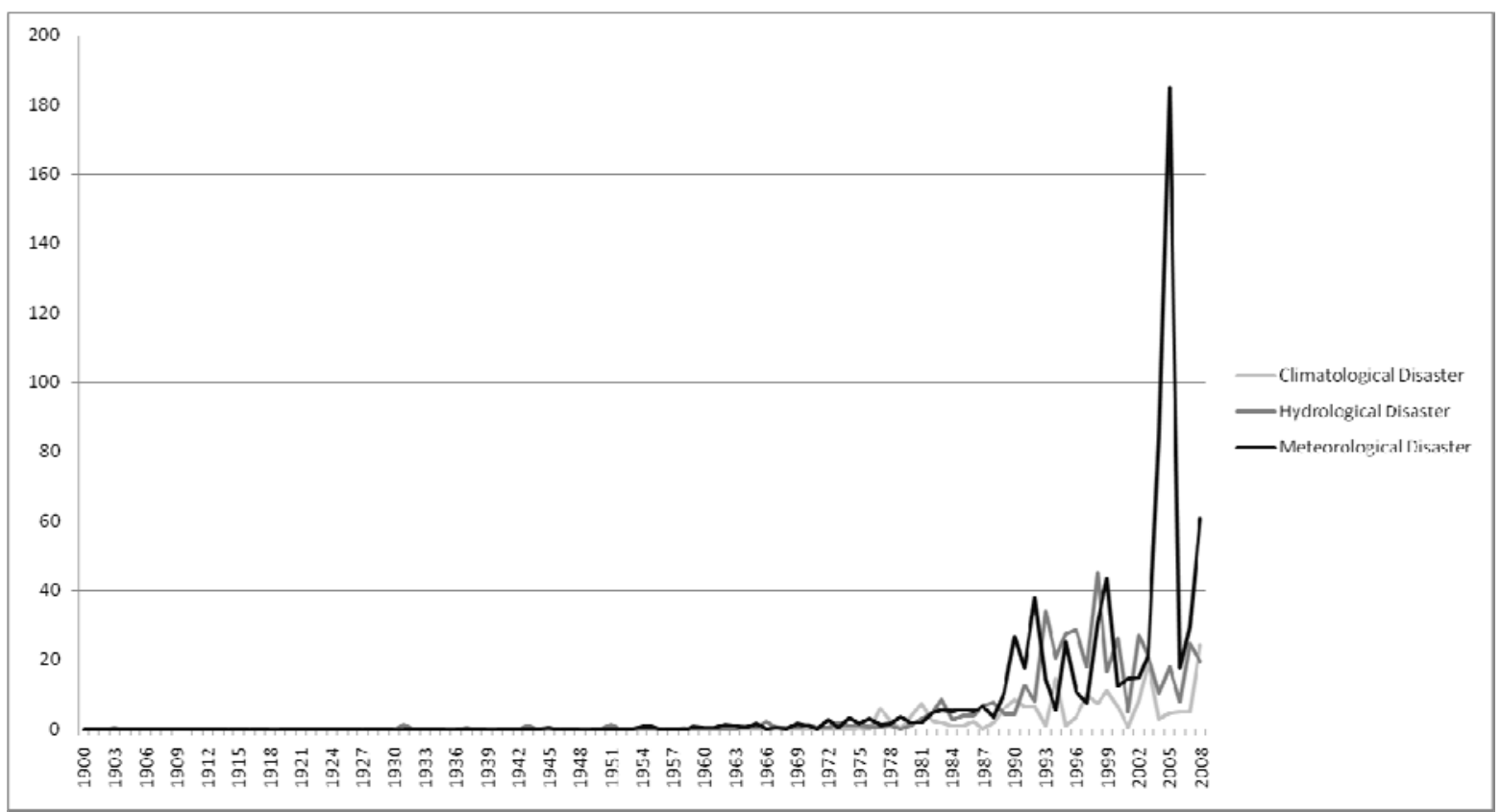


The stylised facts in Figures 1 and 2 illustrate extreme events which have already occurred. ${ }^{6}$ It goes without saying that while the link between global warming and extreme weather events is wellresearched, the possibility of catastrophic events in excess thereof is a far more speculative field. But at higher temperatures, the probability of much more severe catastrophic climate changes may also rise. ${ }^{7}$ These are issues that have sparked considerable current debate and interest. Do non-negligible low-probability tail risks call for an early and significant environmental policy action? How much should we invest now in exchange for benefits in a remote future? What is the appropriate vigour of policy responses in the face of extreme, abrupt climate-change scenarios? This paper tries to come to grips with problems of this type.

To this end we adapt the real option method which has been used for valuing many real-life investment decisions under uncertainty to deal with "tail risk". ${ }^{8}$ Before we develop the model in the next section, some general characteristics of the model are discussed here. An important class of investment and policy decisions is characterized by unrecoverable sunk costs, resolution of uncertainty through time, and the ability to invest in the future as an alternative to investing today. The real options model provides guidance in such settings, including an investment decision rule called the "bad news principle": the downside investment state influences the investment decision whereas the upside investment state is ignored.

It is well-known in finance that daily log-returns do not fit into a Gaussian process or drifted Brownian due to heavy tails, skewness and excess kurtosis. ${ }^{9}$ A heavy-tailed distribution gives a higher probability to extreme events than normal distribution. There are many stochastic processes of heavy-tailed distributions used in finance. Among them is the commonly used Levy process which has independent and stationary increments. The Levy process is simultaneously fairly general and analytically tractable. Many continuous-time stochastic processes are special cases of the general Levy processes, such as the Brownian motion, and Poisson processes. In this paper, we use one-side compound Poisson jumps, combined with a Brownian motion, to model potential sudden swings (large kurtosis and skewness) of global/local social/environmental damage, caused by more frequent

\footnotetext{
${ }^{6}$ The peak in 2005 represents Hurricane Katrina. Hurricane Katrina was the costliest hurricane in the history of the US. Hurricanes are closely related to sea-surface temperatures. Since they started rising in the 1970s, hurricane activity followed the same pattern.

${ }^{7}$ See Weitzman (2009) for a recent discussion of catastrophic risks from climate change and references to the literature on this issue.

${ }^{8}$ The analysis of climate change is confronted with large uncertainties that need to be taken into account to arrive at meaningful policy recommendations. The main contribution of economics to this interdisciplinary task is to provide formal frameworks and techniques for analyzing climate policy in the context of uncertainty. Peterson (2006) and Pindyck (2007) give overviews of existing approaches and findings to provide a broad picture of what economics can contribute to the debate.

${ }^{9}$ A Levy stochastic process is particularly popular in modelling stochastic processes with heavy-tailed distribution. Nontheless the complexity of the processes involved does not hamper reliable modelling. The book "Handbook of Heavy Tailed Distributions in Finance" edited by Rachev (2003) reviews the research on heavy tailed distributions in finance. Among others, further recent papers include Duffie et al. (2000), Cont and Tankov (2004), Kou and Wang (2004), Oksendal and Sulem (2007), and Schoutens (2007).
} 
extreme events from GHG-induced climate changes. ${ }^{10}$ Broadly speaking, the compound Poisson processes in a Levy process show independent random variables with the same intensity as dictated by comparable Poisson processes, but the jump sizes of the random variables are independent and identically distributed with a Levy density. This means that by different parameter values of a Levy density, we can model different types and intensities of extreme events. As the damage from extreme events increases, the environmental policy makers face real options to adopt credible global GHGreduction environmental policies - whether, and when, to commit to such policies by paying (irreversible) huge sunk costs of curbing/reducing GHG levels to reduce the possibility of huge damage by extreme events in the future. The real option tool is widely used and very valuable in identifying and describing choices under uncertainty and irreversibilities. Uncertainties and irreversibilities are central to environmental policies. First, uncertainties over the underlying climatological, geophysical, and hydrological processes exist. These uncertainties are exaccerbated by uncertainty over the exact environmental damage and uncertainty over technological progress that might ameliorate those environmental damages in the future. Second, climate patterns are partly irreversible, i.e. they cannot be fully recovered. ${ }^{11}$

Against this background, we extend Pindyck's (2000) options-based model of irreversible investment which can be readily generalised to include the impact of extreme events. This adds yet another layer of complexity to the climate policy debate. ${ }^{12}$

\section{A Real Options Model of Irreversible Investment with Low-Probability Extreme Events}

This section provides a description of the model. Suppose that the objective of risk-averse policymakers is to maximise the expected discounted flow of utility

$$
W=\int_{0}^{\infty}(\text { social cost of emissions reduction }) e^{-r t} d t-P V(\text { sunk cost }),
$$

where $P V$ is the present value operator and $r$ is the appropriate discount rate. It seems natural to assume that the social cost of emissions reduction is positively related to the GHG pollution stock

\footnotetext{
${ }^{10}$ In contrast, in financial options, it makes sense to use two-sided double (compound) Poisson jumps to capture the heavy-tailed distribution of log-returns. See, for example, Kou and Wang (2003).

${ }^{11}$ Clearly, if the event in question is such that there is time to react to it in case it materialises, then there is no point in trying to preempt the event. Instead, there is an option value of waiting to see if the extreme event materialises and only then take the appropriate action.

${ }^{12}$ Recent advances in theory have made real option valuation techniques applicable to a multitude of real world situations. Because of space limitations, we will not survey the field in detail or provide a thorough description of the tools involved. The interested reader can find a recent introduction to the real options literature in Bertola (2010). For a brief survey of the real options approach in environmental economics, see Pindyck (2007, pp. 5859). So far, no research has evolved on the effects of extreme events and fat tails on the timing of climate policy in real options models. This is perhaps surprising, given that the term "tail risk" is around for quite some time.
} 
level, $M_{t}$, and damages from extreme events due to climate change, $\theta_{t}$. For notational convenience, the expectations operator is suppressed. The sunk costs are related to the irreversible future expenditures of reducing emissions to certain levels over the time once credible environmental policies are adopted. The stock of $M_{t}$ evolves according to

$$
d M_{t}=\left[\beta E_{t}-\delta M_{t}\right] d t
$$

where $E_{t}$ is the emission flow of GHG that controls $M_{t}, \beta$ is a positive parameter, and $\delta$ is the decay rate by which GHG are absorbed by carbon sinks. ${ }^{13}$ For the purpose of climate policy choice, let us consider that the social cost reduction is represented by the concave function

$$
\text { reduced social cost }=-\theta_{t}^{\mu} M_{t} \text {, }
$$

where $\mu \geq 1$ is the social cost function exponent and $\theta_{t}$ denotes the stochastic climate sensitivity parameter. The intuitive concept of irreversibility as a physical constraint can be generalised to include environmental irreversibility as a sunk cost. A higher stochastic climate sensitivity parameter $\theta$ and/or a higher damage function exponent $\mu$ leads to higher damages. ${ }^{14}$

The model treats extreme events probabilistically. Therefore, the next step is to model the underlying uncertainty. In prototypical real option models a Gaussian structure for the shocks driving the dynamics of the economy is assumed. However, the evidence presented above sugests that environmental shocks to the economy are better described by distributions with fat tails. ${ }^{15} \mathrm{We}$ therefore assume that $\theta_{t}$ follows an Ito-Levy process - a geometrical Brownian motion combined with an (asymmetric) Levy jump measure $v$. This provides the most parsimonius framework for us to incorporate both normal and undesirable extreme event risks. Specifically, the stochastic process is described by a (memoryless) compound Poisson process with intensity $\lambda>0$ and jump size distribution density

\footnotetext{
${ }^{13}$ Climate change results not only from pollutants but also from other changes such as rising sea levels and changes in precipitation. Since these are broadly correlated, we use pollutants as a numerical index of the severity of the physical impacts of climate change in general.

${ }^{14}$ Stern (2007), among its other important points, has explored the importance of the damage function exponent. Economic damages from climate change are often assumed to depend upon the square of temperature, but could just as easily be tied to the cube or other power of temperature (measured as degrees above some pre-industrial baseline level). The exponent $\mu$ has been assumed to be constant for mathematical convenience. The alternative would be to treat $\mu$ as a random variable.

${ }^{15}$ Fernández-Villaverde and Rubío-Ramíraz (2007) have recently demonstrated that also several traditional macroeconomic shocks are better described by distributions with fat tails. Therefore the area of application of the theoretical framework below is rather versatile.
} 
(4) $X_{t}=\sum_{i=1}^{N_{t}} Y_{i}$,

where the jump sizes are i.i.d., and $N_{t}$ is a Poisson process with intensity $\lambda$, independent from $\left(Y_{i}\right)_{i \geq 1}$. The compound Poisson processes in a Levy process show independent random variables with the same intensity of the same Poisson process, but the jump sizes of random variables are independent and identically distributed with a Levy density. This means that we can model different extreme events via different parameter values of the Levy density. Note that the Brownian motion part does not enter the Levy measure and both are independent to each other. Applying the Ito-Levy process to the real option framework, we assume that the stochastic process, $\theta$, follows a geometric Brownian motion plus compound jumps

$$
d \theta_{t}=\alpha_{0} \theta_{t} d t+\sigma \theta_{t} d z_{t}+\theta_{t} d X_{t}
$$

where $\alpha_{0}$ is the (predictable) drift parameter of the $\theta$ process, $\sigma$ is the risk parameter, $z$ is the standard Wiener process, and $X$ is defined by equation (4). Equation (5) describes the perturbations governing the dynamics of the system. To make things easier, it is assumed that only positive jumps caused by extreme events increase social costs.

The solution to the problem can now be derived using standard methods. If no environmental policy is adopted to reduce the emissions, then we have the corresponding Bellman equation by applying Ito-Levy lemma, as shown in many books such as Cont and Tankov (2004) and Schoutens (2003):

$$
\begin{aligned}
r W^{\mathrm{N}}=-\theta^{\mu} M+(\beta E- & \delta M) W_{M}^{\mathrm{N}}+\alpha \theta W_{\theta}^{\mathrm{N}}+\frac{1}{2} \sigma^{2} \theta^{2} W_{\theta \theta} \\
& +\int_{-\infty}^{\infty}\left[W^{\mathrm{N}}\left(\theta e^{y}\right)-W^{\mathrm{N}}(\theta)\right] v(d y),
\end{aligned}
$$

where $v(d y)$ is the Levy measure and $\alpha=\alpha_{0}+\int\left(1-e^{y}\right) v(d y)$, corresponding to the $\alpha$ parameter in Pindyck (2000). Partial derivatives are denoted by subscripts. Below we assume a constant aggregate drift parameter $\alpha$. Furthermore we assume that the Levy measure has the one-sided density measure $v(y)=\lambda f(d y)=\lambda \eta e^{-\eta y} d y,=\lambda \eta e^{-\eta y} d y, y>0$. Therefore, equation (6) can be rearranged to obtain 


$$
\begin{aligned}
r W^{\mathrm{N}}=- & \theta^{\mu} M+(\beta E-\delta M) W_{M}^{\mathrm{N}}+\alpha \theta W_{\theta}^{\mathrm{N}} \\
& +\frac{1}{2} \sigma^{2} \theta^{2} W_{\theta \theta}^{\mathrm{N}}+\lambda \int_{0}^{\infty}\left[W^{\mathrm{N}}\left(\theta e^{y}\right)-W^{\mathrm{N}}(\theta)\right] \eta e^{-\eta y} d y,
\end{aligned}
$$

where $W^{\mathrm{N}}$ denotes the social welfare without adopting credible environmental policies, and $f(d y)=\eta e^{-\eta y} d y, \quad y>0$ holds for one-sided jumps - the same Levy density definition as in Kou and Wang (2004). The two positive parameters of the Levy measure, $\lambda$ and $\eta$ show the overall probability of such jump events occurring and the distributions of such jump events over $y$ respectively. It is easy to see that for smaller the values of $\eta$, the extreme events in terms of higher values of $y$ are happening more often. Below we shall see that these two parameters substantially affect the climate policy implications.

If a credible environmental policy is adopted to reduce the emissions such that there are no GHG emissions, then the Bellman equation becomes

$$
r W^{\mathrm{A}}=-\theta^{\mu} M-\delta M W_{M}^{\mathrm{A}}+\alpha \theta W_{\theta}^{\mathrm{A}}+\frac{1}{2} \sigma^{2} \theta^{2} W_{\theta \theta}^{\mathrm{A}}+\lambda \int_{0}^{\infty}\left[W^{\mathrm{A}}\left(\theta e^{y}\right)-W^{\mathrm{A}}\right] \eta e^{-\eta y} d y,
$$

where $W^{\mathrm{A}}$ denotes the social welfare with credible environmental policies. ${ }^{16}$ As explained in Appendix $A$, some manipulation leads to

$$
W^{\mathrm{A}}=-\frac{\theta^{\mu} M}{r+\delta-\alpha \mu-\frac{1}{2} \sigma^{2} \mu(\mu-1)-\frac{\lambda \mu}{\eta-\mu}}, \eta>\mu .
$$

The constraint $\eta>\mu$ ensures that the social welfare value will approach infinity. To solve for optimal climate policy, we also require boundary conditions. Returning to equation (7), it is easy to verify that the solutions of $W^{\mathrm{N}}$ are given by

\footnotetext{
${ }^{16}$ The zero GHG emission assumption has been made along the lines of Pindyck (2000, p. 239) for sake of tractability and mathematical convenience and without loss of generality. This simplification ensures that our model collapses to Pindyck (2000) without extreme events $(\lambda=\eta=0)$. The assumption can easily be relaxed by modifying equation (2) according to $\mathrm{d} M=\phi M \mathrm{~d} t$, where $\phi$ is the net growth rate of $M$.
} 


$$
\begin{aligned}
& W^{\mathrm{N}}=A_{1} \theta^{\gamma_{1}}+A_{2} \theta^{\gamma_{2}}-\frac{\theta^{\mu} M}{r+\delta-\mu \alpha-\frac{1}{2} \mu(\mu-1) \sigma^{2}-\frac{\lambda \mu}{\eta-\mu}} \\
& -\frac{\beta E \theta^{\mu}}{\left(r-\mu \alpha-\frac{1}{2} \mu(\mu-1) \sigma^{2}-\frac{\lambda \mu}{\eta-\mu}\right)\left(r+\delta-\mu \alpha-\frac{1}{2} \mu(\mu-1) \sigma^{2}-\frac{\lambda \mu}{\eta-\mu}\right)},
\end{aligned}
$$

where $A_{1}$ and $A_{2}$ are unknown parameters to be determined by boundary conditions, and the parameters $\gamma_{1}$ and $\gamma_{2}$ are the two positive roots of the following characteristic equation,

$$
\frac{1}{2} \sigma^{2} \gamma^{3}+\left(\alpha-\frac{1}{2}(\eta+1) \sigma^{2}\right) \gamma^{2}-\left(r+\alpha \eta+\lambda-\frac{1}{2} \sigma^{2} \eta\right) \gamma+r \eta=0
$$

From the above analysis, it is obvious that equations (9) and (10) of our more general setting are reduced to Pindyck's (2000) original model once $\lambda=\eta=0$ and $\mu=1$ assumed. The negative root in equation (11) should not cause any confusion. Note that the negative root $\left(\gamma_{3}<0\right)$ of the cubic equation (11) can be omitted when characterising the optimum as we do not consider the option of abandoning the credible environmental policies. This can be seen from the fact that $\lim _{\theta \rightarrow 0} A_{3} \theta^{\mu \gamma_{3}}=\infty$ if $\gamma_{3}$ were negative. But this is not possible. Finally, the assumption $r>\mu \alpha+\mu(\mu-1) \sigma^{2} / 2+\lambda \mu /(\eta-\mu)$ is required to assure that there are no infinite social/environmental costs in equation (9) and (10). From equation (10) we can also obtain an intuitive understanding on how rare events influence intertemporal decion making. Broadly speaking, one can say that the options to adopt credible environmental policies is captured by $A_{1} \theta^{\gamma_{1}}+A_{2} \theta^{\gamma_{2}}$, where $A_{2} \theta^{\gamma_{2}}$ embodies the drift and Wiener processes while $A_{1} \theta^{\gamma_{1}}$ represents the jumps, and hence the extreme events. ${ }^{17}$

To derive the optimal investment rule using dynamic programming, the value-matching condition and the smooth-pasting condition have to be satisfied. The value-matching condition indicates that the marginal value of waiting is equal to the marginal value of investing, or

\footnotetext{
${ }^{17}$ Numerically, $\gamma_{2}$ is slightly smaller than the $\gamma$ parameter of Pindyck (2000), using a drifted geometrical Brownian motion only. And $\gamma_{1}\left(\gamma_{1}>\eta\right)$ is related to the Levy integral only. Thus, we can loosely explain the two options terms accordingly.
} 


$$
\frac{A_{1} \bar{\theta}^{\gamma_{1}}+A_{2} \bar{\theta}^{\gamma_{2}}+K=}{\left(r-\mu \alpha-\frac{1}{2} \mu(\mu-1) \sigma^{2}-\frac{\lambda \mu}{\eta-\mu}\right)\left(r+\delta-\mu \alpha-\frac{1}{2} \mu(\mu-1) \sigma^{2}-\frac{\lambda \mu}{\eta-\mu}\right)},
$$

where $K$ represents present value of sunk cost and $\bar{\theta}$ is the threshold where the society exercises its option to adopt the climate policy and begins abatement. This can be shown mathematically but (12) is is also intuitively simple to understand. The right-hand side of equation (12) denotes the benefit of adopting the policies of reducing GHG; the left-hand side terms are cost of such policies: the real options forgone and the present value of sunk costs in the future. For $\theta>\bar{\theta}$, it is optimal to adopt the GHG-cutting policies. Note that the real options terms are not a function of the level of GHG, as the difference of the particular solutions of the welfare functions with/without environmental policies are only related to $\theta^{\mu}$, not $\theta^{\mu} M$. Finally, we can obtain the corresponding smooth-pasting condition

$$
-\frac{A_{1} \gamma_{1} \bar{\theta}^{\gamma_{1}-1}+A_{2} \gamma_{2} \bar{\theta}^{\gamma_{2}-1}}{\left(r-\mu \alpha-\frac{1}{2} \sigma^{2} \mu(\mu-1)-\lambda \frac{\mu}{\eta-\mu}\right)\left(r+\delta-\mu \alpha-\frac{1}{2} \mu(\mu-1) \sigma^{2}-\lambda \frac{\mu}{\eta-\mu}\right)}=0 .
$$

The solution of the smooth-pasting condition requires a unique point where both the boundary conditions are satisfied. At that point the climate policy must be implemented and policymakers should stop keeping the climate policy option on hold. In other words, the condition ensures that policy is optimally timed. Since the solution sketched out above leads to the three unknown variables $\bar{\theta}, A_{1}$, and $A_{2}$, the third optimality condition

$$
b \frac{\eta}{\eta-\mu} \bar{\theta}-A_{1} \frac{\eta}{\eta-\mu \gamma_{1}} \bar{\theta}^{2 \gamma_{1}-\mu}-A_{2} \frac{\eta}{\eta-\mu \gamma_{2}} \bar{\theta}^{2 \gamma_{2}-\mu}-b+A_{1} \bar{\theta}^{\gamma_{1}-\mu}+A_{2} \bar{\theta}^{\gamma_{2}-\mu}=0
$$

where

$$
a=1 /\left(r-\mu \alpha-\sigma^{2} \mu(\mu-1) / 2-\lambda \mu /(\eta-\mu)\right)
$$

and 
$b=\beta E /\left[\left(r-\mu \alpha-\mu(\mu-1) \sigma^{2} / 2-\lambda \mu /(\eta-\mu)\right)\left(r+\delta-\mu \alpha-\mu(\mu-1) \sigma^{2} / 2-\lambda \mu /(\eta-\mu)\right)\right]$

is needed [see equation (B13) in Appendix B]. Therewith the system has three equations, (12) - (14), and three unknown variables, $A_{1}, A_{2}, \bar{\theta}$, if $\gamma_{1}$ and $\gamma_{2}$ are computed from equation (11).

The model presented above frames the economic analysis of highly uncertain extreme climate events. This provides the platform for the numerical analysis which allows us to solve the optimal stopping problem and solve for the optimal intensity and timing of policy responses.

\section{Model Simulations}

Section 3 has carefully developed and discussed the main features of the model. Unfortunately, the model has no closed form solution for $A_{1}, A_{2}$, and $\bar{\theta}$. This means that we need to use extensive numerical illustrations to gain further insight into the results of the previous section to have a "feel" for the model. The most important goal of these simulations is to see how certain crucial aspects of the model react to changes in parameters. In order to simulate the model, we need to cross the "minefield" of calibration. As methodological issues related to calibration are not the focus of this paper, a pragmatic stance is taken.

As a starting point, we use the benchmark values of Pindyck (2000) $\alpha=0, \delta=0, E=300000, \sigma=$ $0.2, \beta=1.0$, and $K=2 \times 10^{9}{ }^{18}$ We, however, use a slightly lower baseline real interest rate $r=0.03$, as the Stern Review (2007) argues that a lower discount rate should be used for the study of global warming issues. ${ }^{19}$ The baseline parameter for $\mu$ in our global analysis is set to $1.2{ }^{20}$

The calibration of the one-sided positive exponential compound jump distribution for extreme events needs some further consideration. As pointed out by Cont and Tankov (2004, Table 4.3), the probability density function of a Brownian motion with exponential compound jumps is not available in closed form. Therefore, we have to approximate the continuous probability density function (5) using discrete subsamples. In particular, we focus on the ranges for the values of $\lambda$ and $\eta$. The

\footnotetext{
${ }^{18} \sigma=0.2$ is also consistent with recent estimates of implied volatility in the $\mathrm{CO}_{2}$ allowance market (see http://new.evomarkets.com/).

${ }^{19}$ The Stern Review uses a much lower discount rate, 1.5 percent, than the one used in majority of studies on climate change economics. The deterministic trend term $\alpha$ has been assumed to be zero without loss of generality. It may reflect the fact that the recent increase in temperature may be a transient phenomenon in a cyclical process that has no overall long-term trend. For example, a local upswing in an interdecadal sine wave may appear to be a trend when viewed in isolation.

${ }^{20}$ What is most certain is that it is likely to be the poorest countries in the developing world which will be least able to adapt to any increase in the frequency and magnitude of extreme weather phenomena. Weitzman (2009) has demonstrated that in some regions extreme events may lead to very low consumption levels. This implies that welfare losses in those regions become large, and potentially unbounded. In a global analysis those results for a few regions are averaged out, but with a regional focus these fat tails in single regions may drive the analysis. Below we therefore provide a sensitivity analysis with respect to $\mu$.
} 
exponential distribution of compound jumps, $\eta e^{-\eta y}$, implies that when jumps occur, most jumps are small, but sometimes the jumps become much larger, depending on the value of parameter $\eta$ and $\lambda$. Last but not least, the choice of $\eta$ and $\lambda$ is made more difficult by the limited information about extreme event probabilities and their economic impact. Integrated assessment models yield a rough consensus that for temprature increases up to $4^{\circ} \mathrm{C}$, the most likely impact is from 1 percent to 5 percent of GDP. Little is known about the outer tail of the distribution, but there is a real chance, substantiated by recent studies, that temperature increases of 3 percent or 4 percent could have a much larger impact, as high as 8-10 percent of GDP. ${ }^{21}$ Below we assume that the benchmark value for the jump probability $\lambda$ is equal to 6 percent. We then determine a suitable range of $\eta$ parameters such that the extreme event probabilities of different jump sizes are in the right order of magnitude. As no analytical lognomal probability distribution function is available for $\theta$ in equation (5), we use numerical simulations to get a "feel" for the probability density distribution of $\theta$. The technical details of the numerical procedure are discussed below. Formally, equation (5) can be proxied by the Euler scheme

$$
\theta_{t+\Delta t}=\theta_{t}+\alpha \theta_{t} \Delta t+\sigma \theta_{t} \varepsilon_{t} \sqrt{\Delta t}+\theta_{t} \sum_{i=1}^{N} Y_{i}, \quad \varepsilon_{t} \sim N(0 ; 1)
$$

where $Y_{t}$ is simulated from the exponential distribution of $\eta e^{-\eta y} .^{22}$ The intuition behind (15) exactly parallels that of its continuous-time counterpart (5). The distribution of the jumps is proxied by $-\ln$ (uniform distribution of $[0,1]) / \eta$. This implies that the frequency of extreme events ranges from several years to decades or more.

In addition to providing some important intuition behind our results, equation (15) also delivers another important point. The extreme events are governed by the parameters $\eta$ and $\lambda$. Indeed, smaller jumps happen more often for higher value of $\eta$. Conversely, greater disasters happen more often for smaller value of the parameter $\eta$. Technically, in the numerical simulations we pick 1 million random samples of (15) for $\theta_{t}$ with initial values $\theta_{0}=20, \sigma=0.2, \lambda=0.06$, and $\Delta t=0.01$, and each realisation for $\theta$ is calculated for 10 years. The calibrated results in Figure 3 show distinctively that the lognormal probability distribution function depends upon which $\eta$ parameter is at work. The upper graph assumes $\eta=10$, the middle graph assumes $\eta=5$, and the lower graph uses $\eta=3$.

\footnotetext{
${ }^{21}$ For a recent overview of concurrent studies, see Tol (2009). A graphical summary of damage estimates is provided by Dietz and Stern (2008).

${ }^{22}$ The sequential times of Poisson jumps are proxied by $-\ln$ (uniform distribution of $\left.[0,1]\right) / \lambda$. Therefore, when a Poisson jump happens, $\theta$ increases by $\theta_{t}\left(e^{Y_{i}}-1\right)$.
} 
Figure 3: Probability Density Distributions of $\theta$ for $\lambda=0.06$ and $\eta=10, \eta=5$, and $\eta=3$
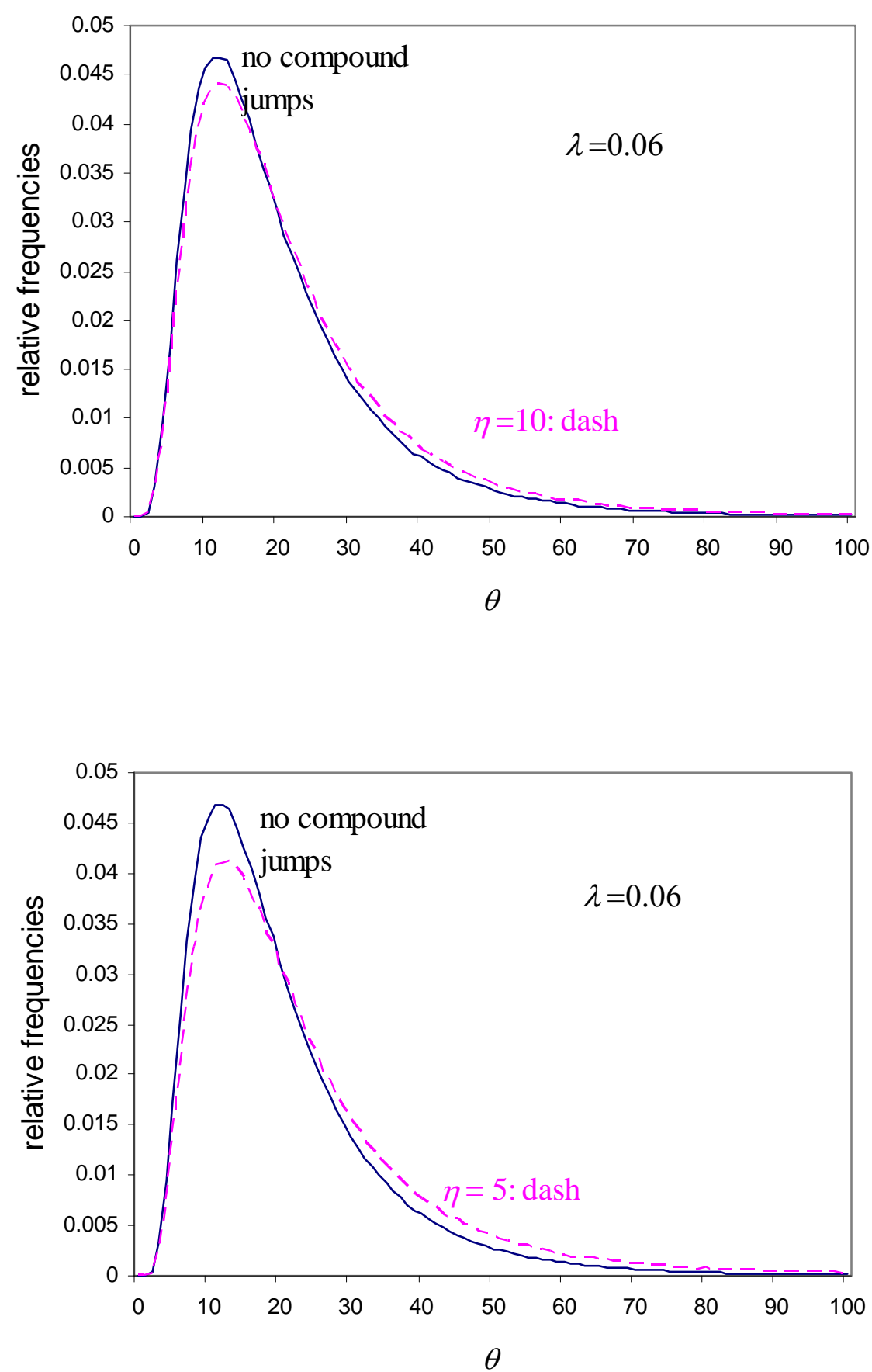


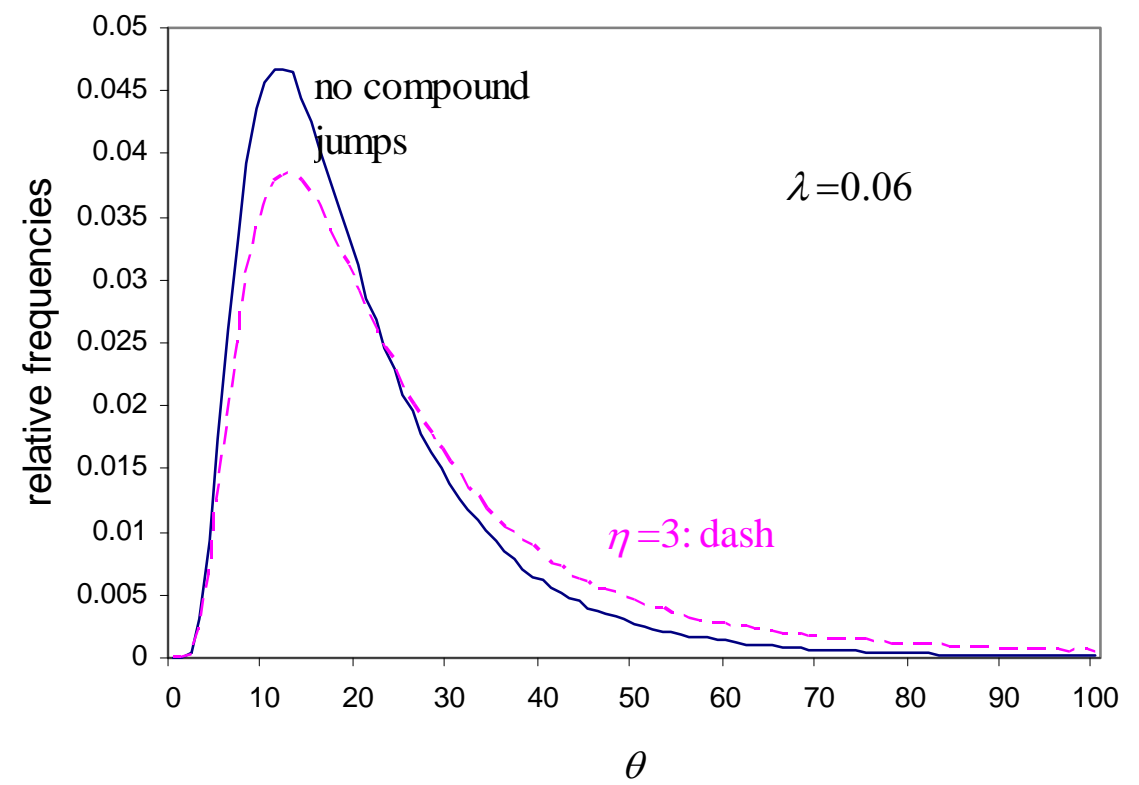

Notes: The probability distribution functions for $\eta=3, \eta=5$, and $\eta=10$ are skewed to the right, and the skewness increases as the value of $\sigma$ increases. The probability distribution functions start at zero, increase to their modes, and decrease thereafter. The solid curves give the geometrical Brownian motion without compound jumps, i.e. without the last term in (15). The dashed curves give the simulated (lognormal) probability density function with jumps.

The features of the distribution are the location of its peak and the shape and extent of the distribtion at large $\theta$. The model specification creates positive skewness in the distribution of $\theta{ }^{23}$ Figure 3 indicates the predominance of the right fat tail in a transparent way. When comparing the Monte Carlo results with jumps (dashed curves) and without jumps (solid curves), it is obvious that for $\eta=$ 10 extreme events are comparatively rare. On the contrary, for $\eta=5$ and $\eta=3$ the distributions are somewhat more stretched out, with more mass in the right tails at the expense of lower modes. One way to reconcile the probability density plots with the data is to calculate the implied probabilities of an extreme event $\theta>\theta^{*}$. Table 1 presents these implied extreme event probabilities from our Monte Carlo exercise. The period under consideration is 10 years.

Due to lack of empirical data, the choice of a baseline parameter for $\eta$ is somewhat arbitrary. If we were to make a best estimate of this, we would choose $\eta=5$ to be broadly consistent with rough and scant estimates of extreme-impact tail probabilities. We therefore use $\lambda=0.06$ and $\eta=5$ as our backof-the-envelope baseline tail estimates in what follows. ${ }^{24}$

\footnotetext{
${ }^{23}$ Roe and Baker (2007) have recently described climate probability distribution functions from the multiensemble climatepredition.net experiment with shapes similar to those in Figure 3. Roe and Baker (2009) have shown that this shape of the distribution is not an artifact of the analysis or choice of model parameters but an inevitable consequence of a system in which complex feedbacks among the individual physical processes are substantially positive.

${ }^{24}$ It goes without saying that the analysis is unavoidably subjective because it requires some form of speculation about bad-fat-tail probabilities. However, the sensitivity analysis below scrutinizes the baseline parameters and thus provides a good grasp of the robustness of the policy implications.
} 
Table 1: Size-Dependent Extreme Event Probabilities for $\lambda=0.06$ in Percent

\begin{tabular}{lcccc}
\hline & No Jumps & $\eta=10$ & $\eta=5$ & $\eta=3$ \\
\hline$\theta>40$ & 8.52 & 10.43 & 13.07 & 16.78 \\
$\theta>50$ & 4.15 & 5.35 & 7.30 & 10.53 \\
$\theta>60$ & 2.14 & 2.88 & 4.29 & 6.99 \\
$\theta>70$ & 1.15 & 1.61 & 2.64 & 4.85 \\
$\theta>80$ & 0.65 & 0.94 & 1.71 & 3.49 \\
\hline
\end{tabular}

Note: The initial $\theta$ is 20 . Therefore, the row $\theta>40$ gives the probability of at least one $\theta$ doubling after 10 years.

Armed with the insights from the Monte Carlo exercise, we now use numerical techniques to solve the optimal stopping problem and calibrate the optimal climate policy response. The graphs gives the critical threshold values $\bar{\theta}$ delimiting the no action area. For $\theta<\bar{\theta}$, it is optimal to wait before adopting a stringent climate policy that imposes large sunk costs on consumers. On the contrary, for $\theta \geq \bar{\theta}$ policymakers will incur the cost of emission reduction to reduce $E_{t}$. The intended contribution of these exercises is to show how the choice of selected parameters alters the policy implications.

By using the above benchmark values of variables, we can then investigate the impacts of changes in variables on the policy thresholds $\bar{\theta}$. Figure 4 shows the impact of changes in $\eta$ over the grid $\eta_{i} \in$ $\{3,11\}$; Figure 5 shows the impact of changes in $\lambda$ over the grid $\lambda_{i} \in\{0.0,0.12\}$. These numerical assumptions span a broad range of possibilities and reflect that our knowledge of the climate system is not of sufficiently high quality to be described with a unique probability distribution. The numerical results in Figure 4 and 5 can be interpreted as follows: For smaller values of $\eta$, greater disasters happen more often leading to a much lower policy threshold $\bar{\theta}$. This implies that an increasing probability of tail risks sharply strengthens the case for earlier reduction of GHG emissions with more stringent climate policies increasing in fatter tails. ${ }^{25}$ Figure 5 indicates the sensitivity of the policy threshold $\bar{\theta}$ with respect to $\lambda$. A larger $\lambda$ implies a larger jump probability. The policy implications are again stark. The numerical results suggest that policymakers need to respond more aggressively to climate change for larger $\lambda$, i.e. optimal policies turn out to be significantly more "conservationist". The numerical results also call into question previous work neglecting such possibilities.

\footnotetext{
${ }^{25}$ This qualitative result is consistent with to the well-known "minimax" strategy in game theory. In these games, the objective is to determine the optimum stake for each separate strategy in order to minimize the maximum gain of the opponents. In climate policy, policymakers are not playing a traditional game but a battle against the forces of nature. Under the minimax rule, a strategy must be selected for which the maximum possible damage is as small as possible.
} 
Figure 4: The Impact of Changes in $\eta$ on the Policy Threshold $\theta$

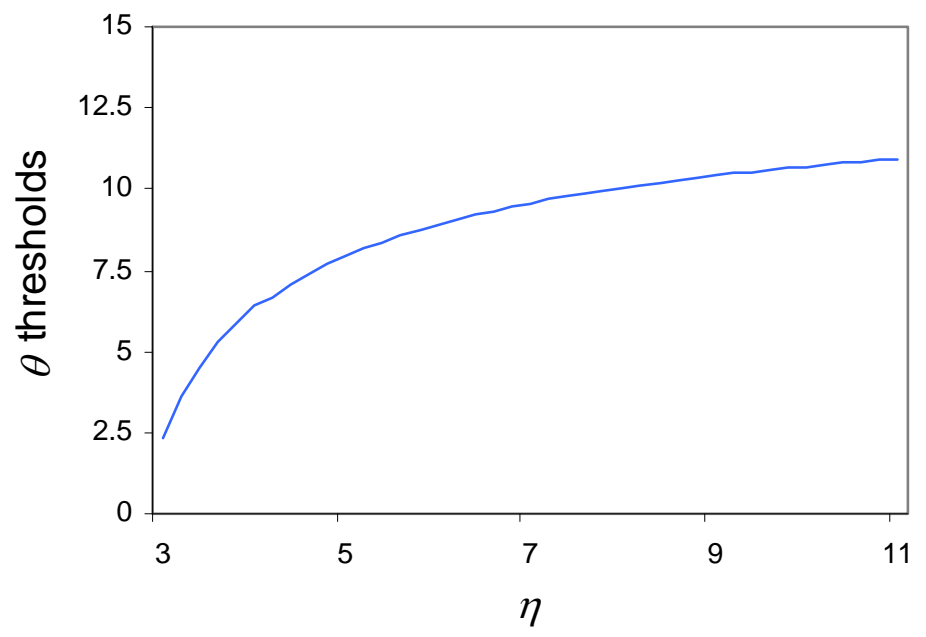

Figure 5: The Impact of Changes in $\lambda$ on the Policy Threshold $\theta$

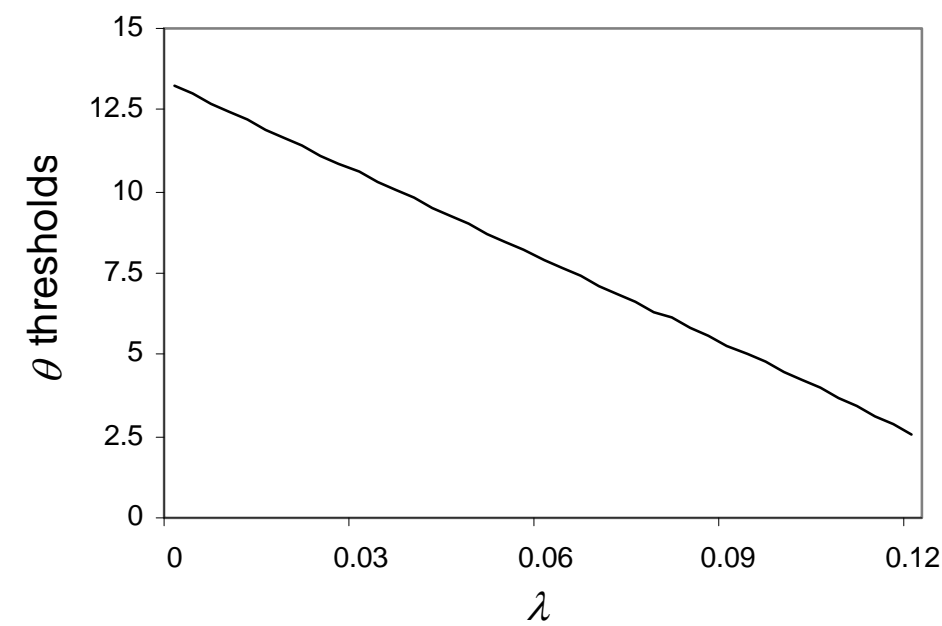

Further to the two-dimensional graphs 4 and 5, we also offer corresponding three-dimensional graphs. The four panels in Figure 6 are from different perspectives, 90 degree rotation for each. This allows to contemplate the results from different perspectives. As is evident from the 3-D graphs in Figure 6, an increase in $\lambda$ and a decrease in $\eta$ leads to a distinctive downward shift of the policy threshold and a corresponding shrinkage of the no action area. 
Figure 6: The Sensitivity of the Policy Threshold to $\lambda$ and $\eta$
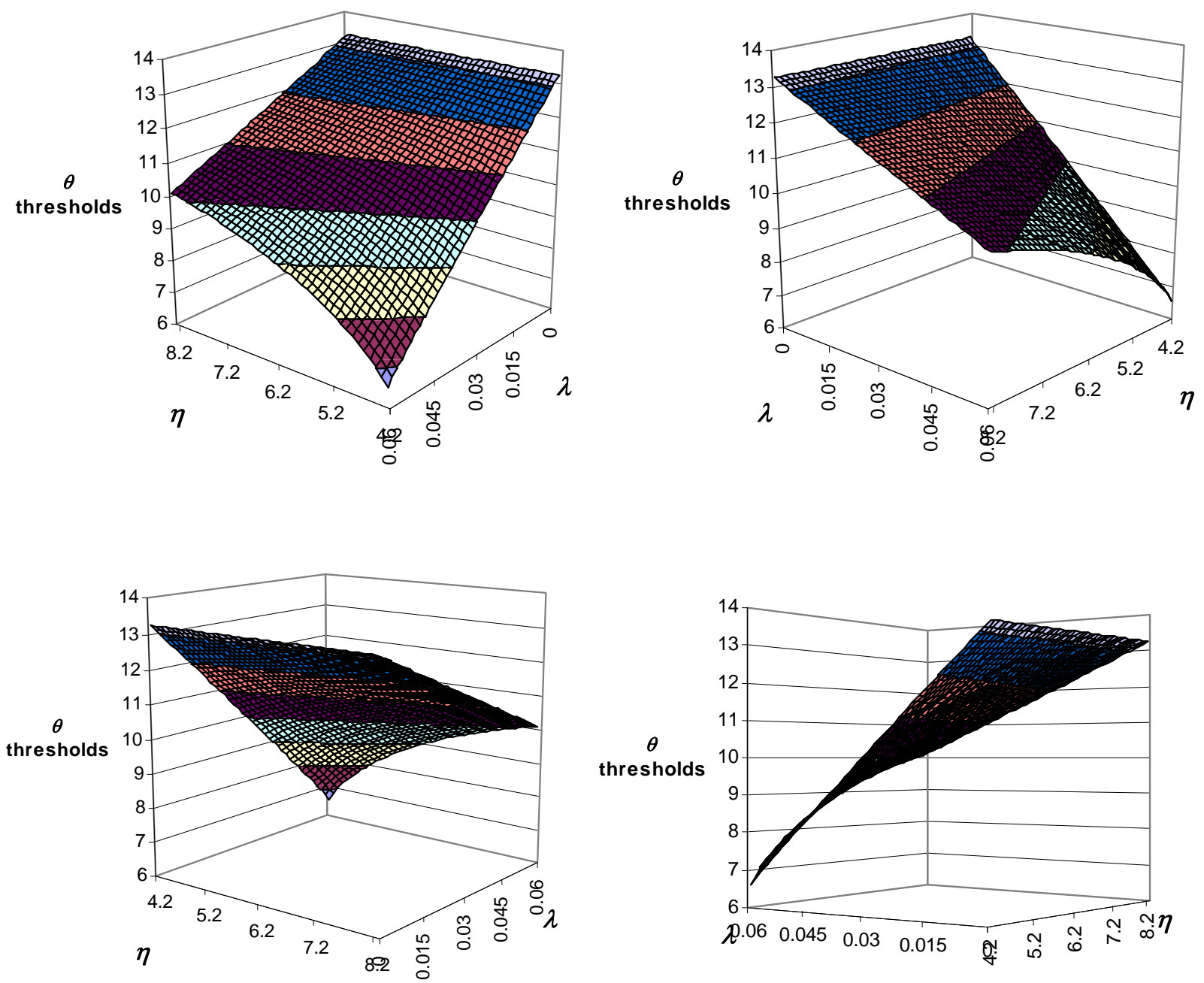

In Figures $4-6$ we have used a counterfactual - and more pessimistic - scenario of $\lambda=0.12$ for the jump probability. In order to allow readers an assessment of the implied risks, we have now calculated the probability density distribution of $\theta$ for $\lambda=0.12$ along the lines of Figure 3 and Table 1. The period under consideration in Table 2 is again 10 years. The comparison between Table 1 and Table 2 shows that extreme events are two to three times more likely for our upper bound $\lambda=0.12$. 
Figure 7: Probability Density Distribution of $\theta$ for $\lambda=0.12$ and $\eta=10, \eta=5$, and $\eta=3$
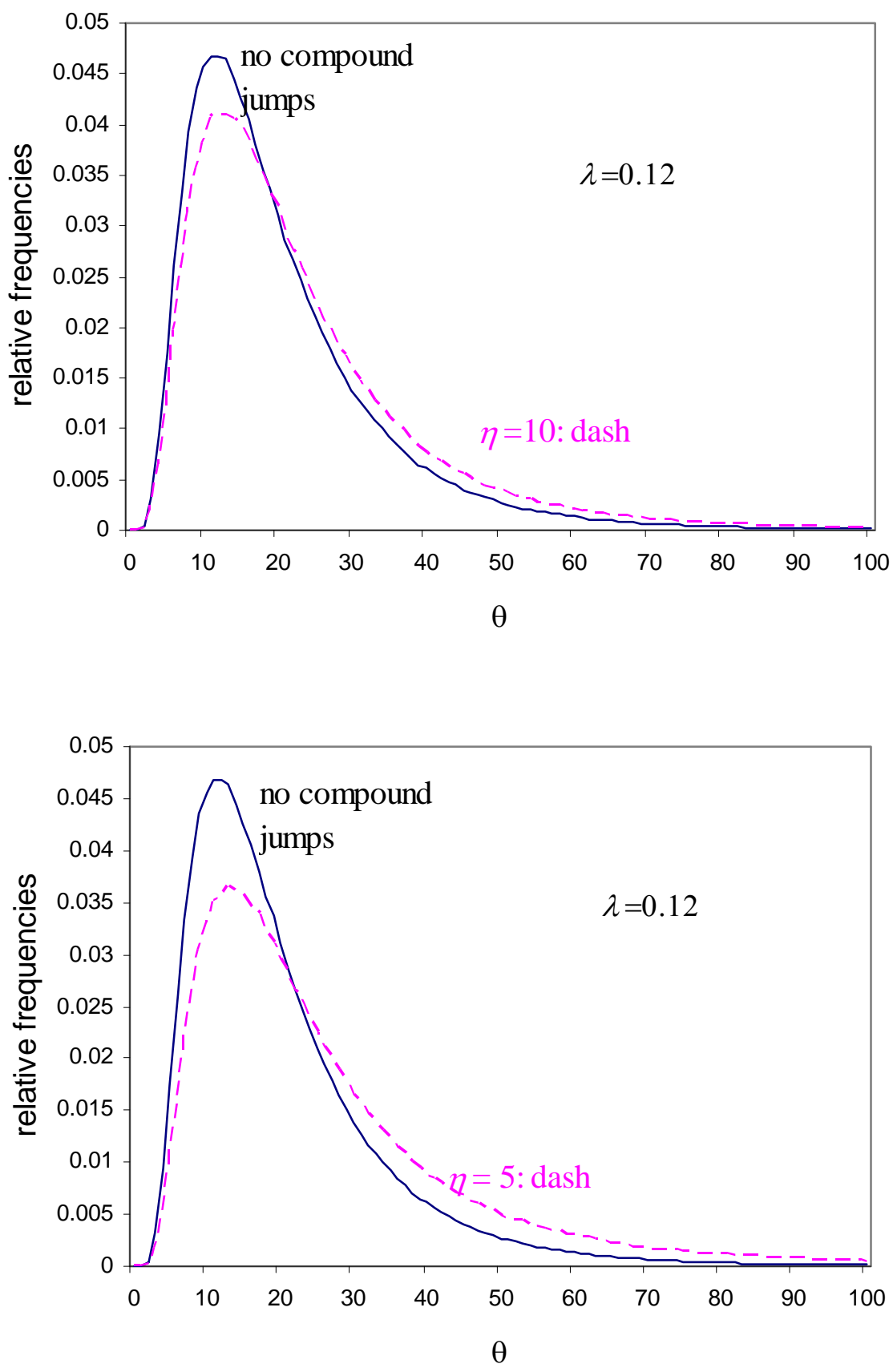


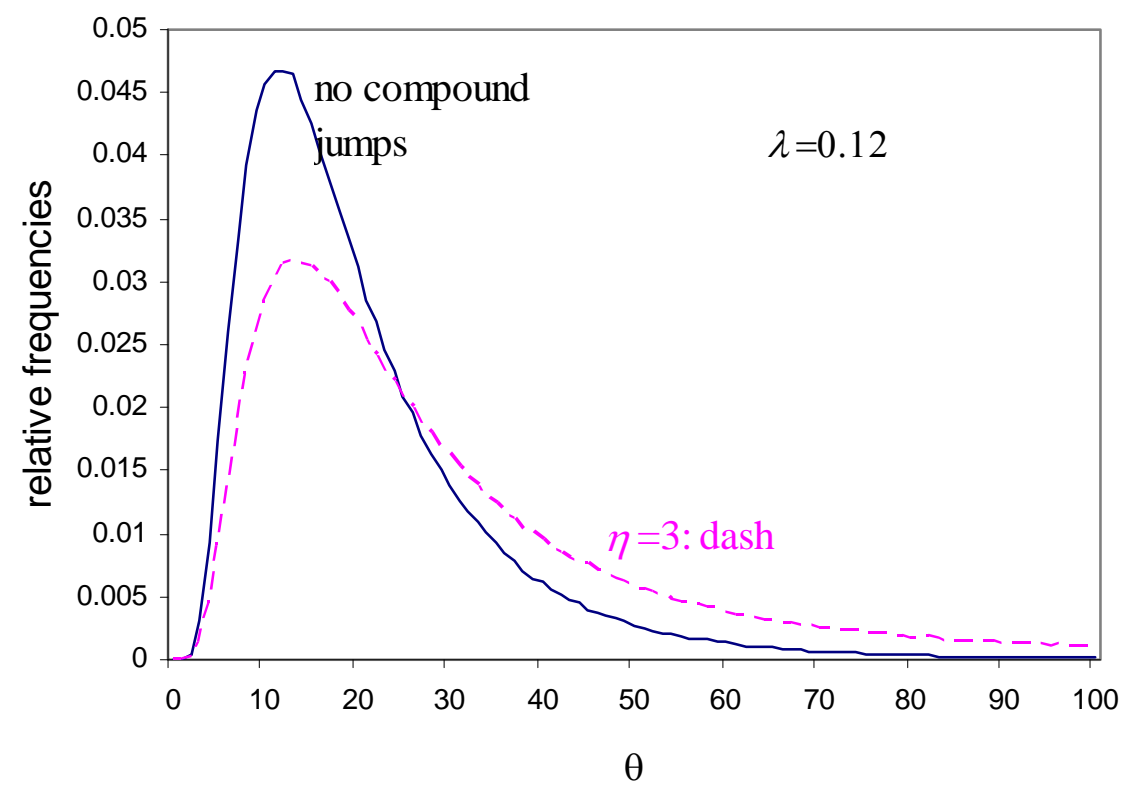

Table 2: Size-Dependent Extreme Event Probabilities for $\lambda=0.12$ in Percent

\begin{tabular}{l|cccc}
\hline & No Jumps & $\eta=10$ & $\eta=5$ & $\eta=3$ \\
\hline$\theta>40$ & 18.33 & 24.24 & 30.93 & 38.44 \\
$\theta>50$ & 8.52 & 12.50 & 18.18 & 25.59 \\
$\theta>60$ & 4.15 & 6.76 & 11.16 & 17.91 \\
$\theta>70$ & 2.14 & 3.81 & 7.19 & 13.09 \\
$\theta>80$ & 1.15 & 2.22 & 4.82 & 9.93 \\
\hline
\end{tabular}

Note: The initial $\theta_{0}$ is 20 . Therefore, the row $\theta>40$ gives the probability of one $\theta$ doubling after 10 years.

Similarly, we can determine the dependence of $\bar{\theta}$ on other parameters. In Figure 8 we investigate how strongly our conclusions would change if we were to adopt a lower discount rate. The Stern Report (2007) represented a break with earlier climate economics modelling approaches in several respects. ${ }^{26}$ The most widely discussed innovation was Stern's (2007) discount rate of just over 1 percent, which is well outside the consensus range. To explore the sensitivity to alternative discounting assumptions, we employ a range of $0.02<r<0.04$. As expected, the results in Figure 8 affirms the view that higher discount rates will bolster the reasons for taking a "wait and see" attitude" towards climate policy. This is due to the fact that for small $r$ the particular integral is a

\footnotetext{
${ }^{26}$ For the discussion of the report, see "Special Topic: The Stern Review Debate" in the journal Climatic Change 89 (2008), No. 3-4, 173-449. We don't consider $r=0$, i.e. an elimination of the time preference rate [Azar and Sterner (1996)] because the particular integral goes to infinity for $r<0.016$ and therefore the system explodes. Another alternative to changing the classic discount rate is hyperbolic discounting. A growing literature hypothesizes that the discount rate placed on future projects declines as a project moves further into the future [Heal, 1997)]. In other words, in the near future (e.g. 5 years) the preferred discount rate is very high. However, as the time horizon extends, the preferred discount rate declines significantly.
} 
good deal bigger and therefore the intertemporal damage is substantially larger. Conversely, a higher discounting factor will trigger a later adoption and a lower intensity of climate policy. This highlights the importance of attaining a consensus on the discount rate before an appraisal on the optimal timing of policy implementation can be achieved.

\section{Figure 8: The Impact of the Discount Rate $r$ on the Policy Threshold}

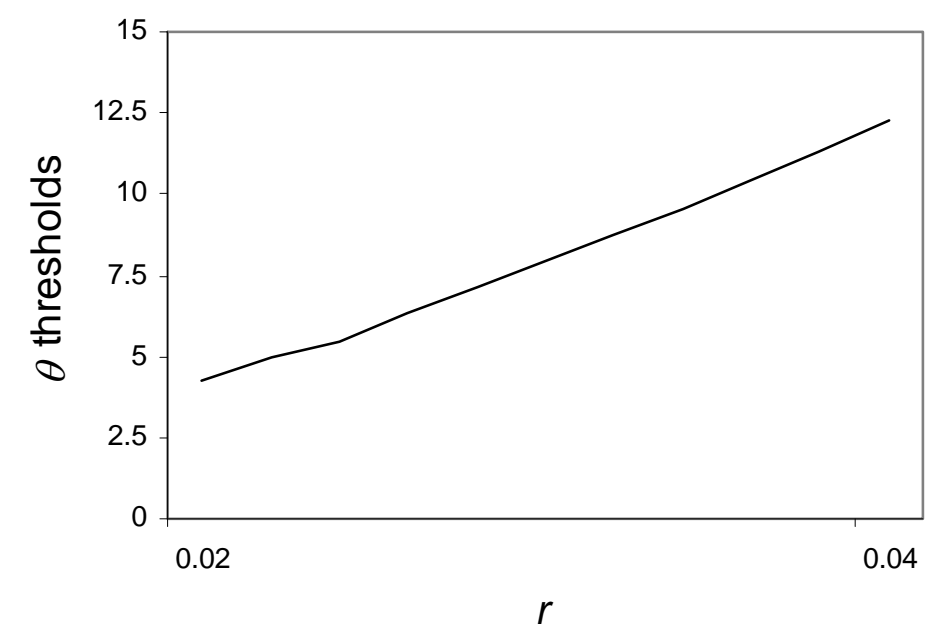

Figure 9 shows the sensitivity of the policy threshold $\bar{\theta}$ to changes in $\sigma$. Contrary to standard real option models, $\bar{\theta}$ is not a monotonically increasing function of $\sigma$. Rather, the resulting relationship turns out to be hump-shaped. At the outset, an increase in $\sigma$ implies an increase in the policy threshold $\bar{\theta}$. The more uncertainty there is over the future, the greater is the incentive to wait and see rather than adopting the policy now. Beyond the inflection point, this goes into reverse. The reason is that in our framework $\sigma$ also affects the particular solution via $\theta^{\mu}, \mu>1$. This effect counteracts the traditional option effect. 
Figure 9: The Sensitivity of the Policy Threshold to Changes in $\sigma$

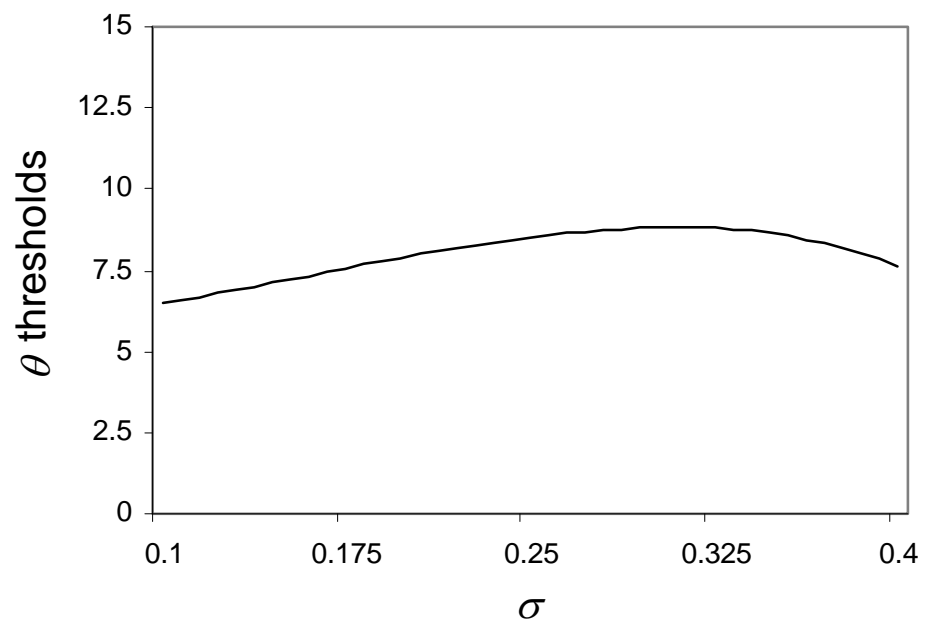

Putting aside the debates over the "correct" values for $\lambda, \eta, r$, and $\sigma$, let us finally consider the importance of the damage function exponent $\mu$. How much would optimal policies be changed due to variation in this parameter?

Figure 10: The Impact of $\mu$ on the Policy Threshold

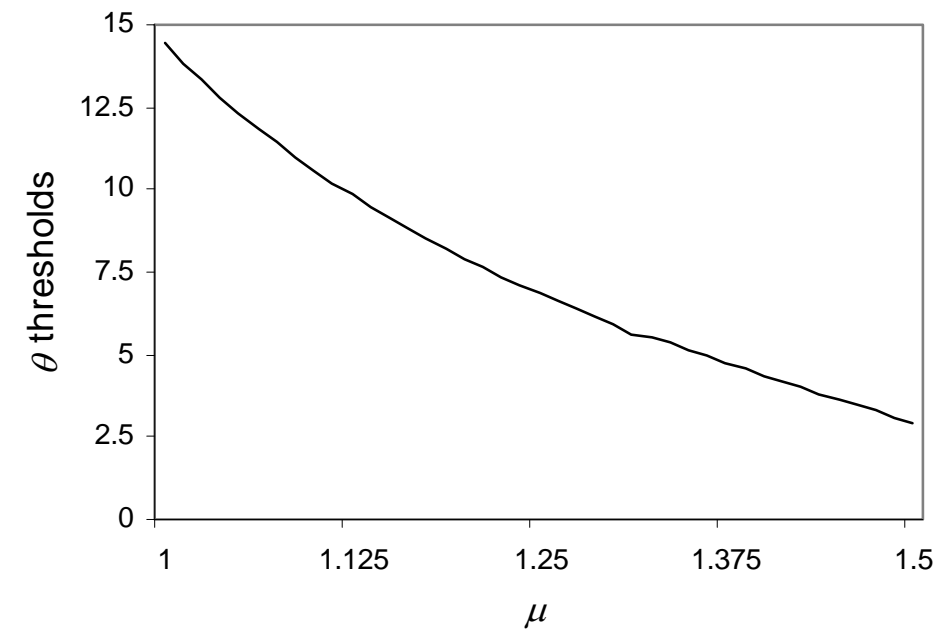

The solution exhibits the properties that one would expect. The effect of $\mu$ is stark, far bigger than extreme events parameters themselves. This means that if the extreme events cause convex (much bigger) damages, then governments should act much earlier. Only when parameter values $\mu>2$ is immediate action motivated. The reason is that exercising the climate policy option incurs large sunk costs, while inaction only involves emissions over the waiting period. The underlying incentive for adopting a "wait and see" stance is that in the future we may receive more data, learn more about 
climate sensitivity, the economic impact of higher temperatures, and develop low-carbon technologies. ${ }^{27}$

\section{Summary and Conclusions}

The possibility of low-probability extreme events calls for a fresh look at the optimal intensity and timing of climate policy. The contribution of this paper is to develop a modelling framework to formally investigate tail risk implications. More specifically, we specify a continuous-time real option model more general than those used by others in that it includes low probability extreme events. At the very least, the numerical calibrations indicate the importance of "tail risk". Despite the high level of abstraction, the framework provides guidance for deciding the conditions and timing under which to take pre-emptive climate policy measures under low-probability fat tail risk. Although our numerical results are only meant to be illustrative, we believe they should be taken into consideration by the policy community. ${ }^{28}$

The numerical results above, combined with our previous brief review of what is known about extreme events, formally investigate tail risk implications. Although we believe that a hierachy of models of increasing comprehensiveness will eventually need to be used in order to refine the basic insights we provide here, policymakers should nevertheless actively overcome the common bias towards undervaluing extreme events. In this spirit, the modelling framework can lead policymakers to improve the valuation of climate change which occurs with great uncertainty or low probability and target an important set of low-probability possibilities in a sensible way.

\footnotetext{
${ }^{27}$ The model calibrations provide insights into the nature of optimal timing and intensity of climate policy under uncertainty, but the results do not readily translate into a policy manual. What the results do tell us, however, is that the right hand tail for $\theta$ matters a lot, and unfortunately we do know comparatively little about that tail. Furthermore, the calibrated extreme event risks also need to be weighted against a variety of other risks societies face.

${ }^{28}$ When facing low-probability extreme events, policymakers often have an incomplete, or vague knowledge of all the possible future states of the world. In such circumstances, called Knightian uncertainty, the states of the world encompassed in the decision-making process are typically not exhaustive.
} 


\section{Appendix A: Derivation of Equation (9)}

We conjecture that $W^{\mathrm{A}}$ under the Levy process setting is of the form

$$
W^{\mathrm{A}}=-c \theta^{\mu} M
$$

where $c$ is an unknown parameter to be determined by equation (8) in the text. We then have the following relationship,

$$
\begin{aligned}
& -\delta M W_{M}^{\mathrm{A}}=+c \delta \theta^{\mu} M \\
& \alpha \mu \theta^{\mu} W_{\theta}^{\mathrm{A}}=-c \alpha \mu \theta^{\mu} M
\end{aligned}
$$

(A4) $\frac{1}{2} \sigma^{2} \theta^{2} W_{\theta \theta}^{\mathrm{A}}=-\frac{1}{2} c \sigma^{2} \mu(\mu-1) \theta^{\mu} M$

The Levy integral term of $W^{\mathrm{A}}$ needs to be handled with care. Once a credible policy is adopted, there is no opting out option. Therefore, thoughts have to be given to integral $\lambda \int_{0}^{\infty}\left[W^{A}\left(\theta e^{y}\right)-W^{A}\right] \eta e^{-\eta y} d y$ even when the value of $\theta$ falls below the threshold value $\bar{\theta}$, as it is an irreversible decision.

$$
\lambda\left[\int_{0}^{\infty}\left[-c \theta^{\mu} e^{\mu y} M-\left(-c \theta^{\mu} M\right)\right] \eta e^{-\eta y} d y\right]=-\lambda \eta c \theta^{\mu} M\left(\frac{1}{\eta-\mu}-\frac{1}{\eta}\right)=-\lambda c \theta^{\mu} M \frac{\mu}{\eta-\mu}
$$

where the constraint $\eta>\mu$ is needed to avoid the infinity of the integral. Substituting equations (A1)-(A5) back to equation (8) in the text yields

$$
-c r \theta^{\mu} M=-\theta^{\mu} M+c \delta \theta^{\mu} M-c \alpha \mu \theta^{\mu} M-\frac{1}{2} c \mu(\mu-1) \sigma^{2} \theta^{\mu} M-\frac{\lambda \mu c \theta^{\mu} M}{\eta-\mu}
$$

Rearranging the above equation gives

$$
\theta^{\mu} M\left(-c\left(r+\delta-\alpha \mu-\frac{1}{2} \mu(\mu-1) \sigma^{2}-\frac{\lambda \mu}{\eta-\mu}\right)+1\right)=0
$$

Using (A7), it is a straightforward calculation to show that

$$
c=\frac{1}{r+\delta-\alpha \mu-\frac{1}{2} \mu(\mu-1) \sigma^{2}-\frac{\lambda \mu}{\eta-\mu}}
$$

which yields equation (9) in the text.

Appendix B: Derivation of Equations (10), (11), and (13) 
In this appendix, we derive equation (13) in the main text. To get the solution of the model, we need to compute $W^{\mathrm{N}}$, and we do so by conjecturing that

$$
W^{\mathrm{N}}=-a \theta^{\mu} M-b \theta^{\mu}+A \theta^{\gamma} .
$$

We then have the following relationship,

$$
(\beta E-\delta M) W_{M}^{\mathrm{N}}=-a \beta E \theta^{\mu}+a \delta \theta^{\mu} M
$$

$$
\alpha \theta W_{\theta}^{\mathrm{N}}=-a \mu \alpha \theta^{\mu} M-b \alpha \mu \theta^{\mu}+A \alpha \gamma \theta^{\gamma}
$$

$$
\frac{1}{2} \sigma^{2} \theta^{2} W_{\theta \theta}^{\mathrm{N}}=\frac{1}{2} \sigma^{2}\left[-a \mu(\mu-1) \theta^{\mu} M-b \mu(\mu-1) \theta^{\mu}+\gamma(\gamma-1) A \theta^{\gamma}\right]
$$

The Levy integral needs to be computed by the optimal stopping algorithm. If $\theta<\bar{\theta}$, then no environmental policy is adopted and the value for $W^{\mathrm{N}}$ is denoted by (B1); if $\theta \geq \bar{\theta}$, then the policy is adopted and sunk cost is paid when the options are exercised. Thus, the value becomes $W^{\mathrm{A}}-K$. The Levy integral then becomes

$$
\begin{aligned}
& \lambda \int_{0}^{\infty}\left[W^{\mathrm{N}}\left(\theta e^{y}\right)-W^{\mathrm{N}}(\theta)\right] f(y) d y \\
& =\lambda \int_{0}^{\ln \bar{\theta}}\left[W^{\mathrm{N}}\left(\theta e^{y}\right)-W^{\mathrm{N}}(\theta)\right] \eta e^{-\eta y} d y+\lambda \int_{\ln \bar{\theta}}^{\infty}\left[W^{\mathrm{A}}\left(\theta e^{y}\right)-W^{\mathrm{A}}(\theta)\right] \eta e^{-\eta y} d y .
\end{aligned}
$$

The first integral, $\lambda \int_{0}^{\ln \bar{\theta}}\left[W^{\mathrm{N}}\left(\theta e^{y}\right)-W^{\mathrm{N}}(\theta)\right] \eta e^{-\eta y} d y$, is solved as follows:

$$
\begin{aligned}
& \lambda \int_{0}^{\ln \bar{\theta}}\left[W^{\mathrm{N}}\left(\theta e^{y}\right)-W^{\mathrm{N}}(\theta)\right] \eta e^{-\eta y} d y \\
& =\lambda \int_{0}^{\ln \bar{\theta}}\left[-a\left(\theta e^{y}\right)^{\mu} M-b\left(\theta e^{y}\right)^{\mu}+A\left(\theta e^{y}\right)^{\gamma}+a \theta^{\mu} M+b \theta^{\mu}-A \theta^{\gamma}\right] \eta e^{-\eta y} d y \\
& =-a \lambda \eta \theta^{\mu} M \int_{0}^{\ln \bar{\theta}} e^{-(\eta-\mu) y} d y-b \lambda \eta \theta^{\mu} \int_{0}^{\ln \bar{\theta}} e^{-(\eta-\mu) y} d y \\
& +A \lambda \eta \theta^{\gamma} \int_{0}^{\ln \bar{\theta}} e^{-(\eta-\gamma) y} d y+a \lambda \eta \theta^{\mu} M \int_{0}^{\ln \bar{\theta}} e^{-\eta y} d y \\
& +b \lambda \eta \theta^{\mu} \int_{0}^{\ln \bar{\theta}} e^{-\eta y} d y-A \lambda \eta \theta^{\gamma} \int_{0}^{\ln \bar{\theta}} e^{-\eta y} d y
\end{aligned}
$$

Thus, we have

$$
\begin{aligned}
& \lambda \int_{0}^{\ln \bar{\theta}}\left[W^{\mathrm{N}}\left(\theta e^{y}\right)-W^{\mathrm{N}}(\theta)\right] \eta e^{-\eta y} d y \\
& =-a \lambda \frac{\eta}{\eta-\mu} M \theta^{\mu}\left(1-\bar{\theta}^{-(\eta-\mu)}\right)-b \lambda \frac{\eta}{\eta-\mu} \theta^{\mu}\left(1-\bar{\theta}^{-(\eta-\mu)}\right) \\
& +A \lambda \frac{\eta}{\eta-\mu} \theta^{\gamma}\left(1-\bar{\theta}^{-(\eta-\mu)}\right)+a \lambda M \theta^{\mu}\left(1-\bar{\theta}^{-\eta}\right)+b \lambda \theta^{\mu}\left(1-\bar{\theta}^{-\eta}\right)-A \lambda \theta^{\gamma}\left(1-\bar{\theta}^{-\eta}\right) .
\end{aligned}
$$


Similarily, the second integral, $\lambda \int_{\ln \bar{\theta}}^{\infty}\left[W^{\mathrm{A}}\left(\theta e^{y}\right)-W^{\mathrm{A}}(\theta)\right] \eta e^{-\eta y} d y$, is solved as follows:

(B7)

$$
\begin{aligned}
& \lambda \int_{\ln \bar{\theta}}^{\infty}\left[W^{\mathrm{A}}\left(\theta e^{y}\right)-W^{\mathrm{A}}(\theta)\right] \eta e^{-\eta y} d y \\
& =\lambda \int_{\ln \bar{\theta}}^{\infty}\left[-\frac{\left(\theta e^{y}\right)^{\mu} M}{r+\delta-\alpha \mu-\frac{1}{2} \mu(\mu-1) \sigma^{2}-\frac{\lambda \mu}{\eta-\mu}}+\frac{\theta^{\mu} M}{r+\delta-\alpha \mu-\frac{1}{2} \mu(\mu-1) \sigma^{2}-\frac{\lambda \mu}{\eta-\mu}}\right] \eta e^{-\eta y} d y
\end{aligned}
$$

$$
=-\frac{\lambda \eta \theta^{\mu} M}{r+\delta-\alpha \mu-\frac{1}{2} \mu(\mu-1) \sigma^{2}-\frac{\lambda \mu}{\eta-\mu}} \int_{\ln \bar{\theta}}^{\infty} e^{-(\eta-\mu) y} d y+\frac{\lambda \eta \theta^{\mu} M}{r+\delta-\alpha \mu-\frac{1}{2} \mu(\mu-1) \sigma^{2}-\frac{\lambda \mu}{\eta-\mu}} \int_{\ln \bar{\theta}}^{\infty} e^{-\eta y} d y
$$

The pattern should be clear. Rearranging gives us

$$
\begin{gathered}
\lambda \int_{0}^{\ln \bar{\theta}}\left[W^{\mathrm{A}}\left(\theta e^{y}\right)-W^{\mathrm{A}}(\theta)\right] \eta e^{-\eta y} d y=-\frac{\lambda \frac{\eta}{\eta-\mu} \theta^{\mu} M}{r+\delta-\alpha \mu-\frac{1}{2} \mu(\mu-1) \sigma^{2}-\frac{\lambda \mu}{\eta-\mu}}\left(\bar{\theta}^{-(\eta-\mu)}\right) \\
+\frac{\lambda \theta^{\mu} M}{r+\delta-\alpha \mu-\frac{1}{2} \mu(\mu-1) \sigma^{2}-\frac{\lambda \mu}{\eta-\mu}}\left(\bar{\theta}^{-\eta}\right) .
\end{gathered}
$$

Substituting equations (B2)-(B4), (B6)-(B8) into (7) in the text and re-arranging yields

$$
\begin{aligned}
& \theta^{\mu} M\left[a\left(-r-\delta+\mu \alpha+\frac{1}{2} \mu(\mu-1) \sigma^{2}+\lambda \frac{\mu}{\eta-\mu}\right)+1\right] \\
& +\theta^{\mu}\left[b\left(-r+\mu \alpha+\lambda \frac{\mu}{\eta-\mu}+\frac{1}{2} \mu(\mu-1) \sigma^{2}\right)+a \beta E\right] \\
& +A \theta^{\gamma}\left[r-\alpha \gamma-\frac{1}{2} \sigma^{2} \mu \gamma(\mu \gamma-1)-\lambda \frac{\mu \gamma}{\eta-\mu \gamma}\right] \\
& =-a \lambda \frac{\eta}{\eta-\mu} M \theta^{\mu}\left(-\bar{\theta}^{-(\eta-\mu)}\right)-b \lambda \frac{\eta}{\eta-\mu} \theta^{\mu}\left(-\bar{\theta}^{-(\eta-\mu)}\right)+A \lambda \frac{\eta}{\eta-\mu \gamma} \theta^{\gamma}\left(-\bar{\theta}^{-(\eta-\gamma)}\right) \\
& +a \lambda M \theta^{\mu}\left(-\bar{\theta}^{-\eta}\right)+b \lambda \theta^{\mu}\left(-\bar{\theta}^{-\eta}\right)-A \lambda \theta^{\gamma}\left(-\bar{\theta}^{-\eta}\right) \\
& -\frac{\lambda \frac{\eta}{\eta-\mu} \theta^{\mu} M}{r+\delta-\alpha \mu-\frac{1}{2} \mu(\mu-1) \sigma^{2}-\frac{\lambda \mu}{\eta-\mu}}\left(\bar{\theta}^{-(\eta-\mu)}\right) \\
& +\frac{\lambda \theta^{\mu} M}{r+\delta-\alpha \mu-\frac{1}{2} \mu(\mu-1) \sigma^{2}-\frac{\lambda \mu}{\eta-\mu}}\left(\bar{\theta}^{-\eta}\right) .
\end{aligned}
$$


Equation (B9) holds if the terms in all three brackets of left-hand side are set to zero separately and the term of right-hand hand is equal to zero. Thus, we have

$$
a=\frac{1}{r+\delta-\mu \alpha-\frac{1}{2} \mu(\mu-1) \sigma^{2}-\lambda \frac{\mu}{\eta-\mu}}
$$

$$
b=\frac{\beta E}{\left(r-\mu \alpha-\frac{1}{2} \mu(\mu-1) \sigma^{2}-\frac{\lambda \mu}{\eta-\mu}\right)\left(r+\delta-\mu \alpha-\frac{1}{2} \mu(\mu-1) \sigma^{2}-\frac{\lambda \mu}{\eta-\mu}\right)}
$$

$$
\begin{aligned}
& \frac{1}{2} \sigma^{2} \gamma^{3}+\left(\alpha-\frac{1}{2}(\eta+1) \sigma^{2}\right) \gamma^{2}-\left(r+\alpha \eta+\lambda-\frac{1}{2} \sigma^{2} \eta\right) \gamma+r \eta=0 \\
& a \lambda \frac{\eta}{\eta-\mu} M \theta^{\mu} \bar{\theta}^{-(\eta-\mu)}+b \lambda \frac{\eta}{\eta-\mu} \theta^{\mu} \bar{\theta}^{-(\eta-\mu)}-A \lambda \frac{\eta}{\eta-\mu \gamma} \theta^{\gamma} \bar{\theta}^{-(\eta-\gamma)}-a \lambda M \theta^{\mu} \bar{\theta}^{-\eta}-b \lambda \theta^{\mu} \bar{\theta}^{-\eta}
\end{aligned}
$$

$$
+A \lambda \theta^{\gamma} \bar{\theta}^{-\eta}-\frac{\lambda \frac{\eta}{\eta-\mu} \theta^{\mu} M \bar{\theta}^{-(\eta-\mu)}}{r+\delta-\alpha \mu-\frac{1}{2} \mu(\mu-1) \sigma^{2}-\frac{\lambda \mu}{\eta-\mu}}+\frac{\lambda \theta^{\mu} M \bar{\theta}^{-\eta}}{r+\delta-\alpha \mu-\frac{1}{2} \mu(\mu-1) \sigma^{2}-\frac{\lambda \mu}{\eta-\mu}}=0
$$

(B13) can be streamlined by multiplying $\bar{\theta}^{\eta-\mu} / \lambda$, setting $\theta=\bar{\theta}$ for thresholds of adopting the credible environmental policies, and substituting equations (B10) and (B11). Thus, equation (12) can be rewritten as

$$
b \frac{\eta}{\eta-\mu} \bar{\theta}^{\mu}-A \frac{\eta}{\eta-\mu \gamma} \bar{\theta}^{2 \gamma-\mu}-b+A \bar{\theta}^{\gamma-\mu}=0
$$

There are two positive characteristic roots $\left(\gamma_{1}>\gamma_{2}>0\right)$ and one negative root $\left(\gamma_{3}\right)$ of equation (B12). As we do not consider the options to abandon the credible environmental policies, we can ignore the answer related to $\gamma_{3}$ as $\lim _{\theta \rightarrow 0} A_{3} \theta^{\mu \gamma_{3}}=\infty$. Thus, equation (B1) becomes

$$
\begin{aligned}
W^{\mathrm{N}}= & A_{1} \theta^{\gamma_{1}}+A_{2} \theta^{\gamma_{2}}-\frac{\theta^{\mu} M}{r+\delta-\mu \alpha-\frac{1}{2} \mu(\mu-1) \sigma^{2}-\frac{\lambda \mu}{\eta-\mu}} \\
& -\frac{\beta E}{\left(r-\mu \alpha-\frac{1}{2} \mu(\mu-1) \sigma^{2}-\frac{\lambda \mu}{\eta-\mu}\right)\left(r+\delta-\mu \alpha-\frac{1}{2} \mu(\mu-1) \sigma^{2}-\frac{\lambda \mu}{\eta-\mu}\right)}
\end{aligned}
$$

which is equation (13) in the text, and equation (B14) becomes

$$
b \frac{\eta}{\eta-\mu} \bar{\theta}-A_{1} \frac{\eta}{\eta-\mu \gamma_{1}} \bar{\theta}^{2 \gamma_{1}-\mu}-A_{2} \frac{\eta}{\eta-\mu \gamma_{2}} \bar{\theta}^{2 \gamma_{2}-\mu}-b+A_{1} \bar{\theta}^{\gamma_{1}-\mu}+A_{2} \bar{\theta}^{\gamma_{2}-\mu}=0
$$




\section{References:}

Azar, C., Sterner, T. (1996) "Discounting and Distributional Considerations in the Context of Global Warming”, Ecological Economics 19, 169-185.

Bertola, G. (2010) ”Options, Inaction, and Uncertainty”, Scottish Journal of Political Economy 57, 254-271.

Boyarchenko, S.I. and S.Z. Levendorskií (2002) "Perpetual American Options Under Lévy Processes”, SIAM Journal on Control and Optimization, 40, 1663-1696.

Box, G.E.P. and M.E. Muller (1958) “A Note on the Generation of Random Normal Deviates", Annals Mathematical. Statistics 29, 610-611.

Cont, R. and P. Tankov (2004) Financial Modelling with Jump Processes, London (Chapman \& Hall).

Dietz, S. and N. Stern (2008) "Why Economic Analysis Supports Strong Action on Climate Change: A Response to the Stern Review's Critic's”, Review of Environmental Economics and Policy 2, 94113.

Dixit, A. and R.S. Pindyck (1994) Investment Under Uncertainty, Princeton (Princeton University Press).

Fernández-Villaverde, J. and J. Rubío-Ramírez (2007) "Estimating Macroeconomic Models: A Likelihood Approach”, Review of Economic Studies 74, 1059-1087.

Heal, G. (1997) “Discounting and Climate Change”, Climatic Change 37, 335-343.

Hoyos, C.D., Agudelo, P.A., Webster, P.J. and J.A. Curry (2006) "De-Convolution of the Factors Contributing to the Increase in Global Hurricane Intensity”, Science 312, 94-97.

Intergovermental Panel on Climate Change (2008) Climate Change 2007: Impacts, Adaptation and Vulnerability, Cambridge (Cambridge University Press).

Oksendal, B. and A. Sulem (2007) Applied Stochastic Control of Jump Diffusions, $2^{\text {nd }}$ edition, Berlin \& New York (Springer).

Peterson, S. (2006) "Uncertainty and Economic Analysis of Climate Change: A Survey of Approaches and Findings”, Environmental Modeling and Assessment 11, 1-17.

Pindyck, R.S. (2000) "Irreversibilities and the Timing of Environmental Policy", Resource and Energy Economics 22, 233-259.

Pindyck, R.S. (2002) “Optimal Timing Problems in Environmental Economics”, Journal of Economic Dynamics and Control 26, 1677-1697.

Pindyck, R.S. (2007) "Uncertainty in Environmental Economics", Review of Environmental Economics and Policy 1, 45-65. 
Press, W.H., Teukolsky, S.A., Vetterling, W.T. and B.P. Flannery (1992) Numerical Recipes in C: The Art of Scientific Computing, 2nd edition, Cambridge (Cambridge University Press).

Rachev, S. T. (2003) Handbook of Heavy Tailed Distributions in Finance: Handbooks in Finance, Amsterdam (North Holland).

Roe, G.H. and M.B. Baker (2007) "Why is Climate Sensitivity So Unpredictable?”, Science 318, 26 October 2009, 629-632.

Stern, N. (2007) The Economics of Climate Change - The Stern Review, Cambridge (Cambridge University Press).

Stokey, N.L. (2008) The Economics of Inaction: Stochastic Control Models with Fixed Costs, Princeton (Princeton University Press).

Schoutens, W. (2003) Levy Processes in Finance: Pricing Financial Derivatives, Oxford (Wiley \& Blackwell).

Tol, R. (2009) “The Economic Effects of Climate Change”, Journal of Economic Perspectives 23, 29-51.

Tsur, Y. and A. Zemel (1996) “Accounting for Global Warming Risks: Resource Management under Event Uncertainty”, Journal of Economic Dynamics and Control 20, 1289-1305.

Webster, P.J., Holland, G.J., Curry, J.A. and H.-R. Chang (2005) "Changes in Tropical Cyclone Number, Duration, and Intensity in a Warming Environment”, Science 309, 1844-1846.

Weitzman, M. (2009) "On Modeling and Interpreting the Economics of Catastrophic Climate Change”, The Review of Economics and Statistics 91, 1-19. 


\section{CESifo Working Paper Series}

for full list see www.cesifo-group.org/wp

(address: Poschingerstr. 5, 81679 Munich, Germany, office@cesifo.de)

3077 Alessandro Cigno, How to Deal with Covert Child Labour, and Give Children an Effective Education, in a Poor Developing Country: An Optimal Taxation Problem with Moral Hazard, June 2010

3078 Bruno S. Frey and Lasse Steiner, World Heritage List: Does it Make Sense?, June 2010

3079 Henning Bohn, The Economic Consequences of Rising U.S. Government Debt: Privileges at Risk, June 2010

3080 Rebeca Jiménez-Rodriguez, Amalia Morales-Zumaquero and Balázs Égert, The VARying Effect of Foreign Shocks in Central and Eastern Europe, June 2010

3081 Stephane Dees, M. Hashem Pesaran, L. Vanessa Smith and Ron P. Smith, Supply, Demand and Monetary Policy Shocks in a Multi-Country New Keynesian Model, June 2010

3082 Sara Amoroso, Peter Kort, Bertrand Melenberg, Joseph Plasmans and Mark Vancauteren, Firm Level Productivity under Imperfect Competition in Output and Labor Markets, June 2010

3083 Thomas Eichner and Rüdiger Pethig, International Carbon Emissions Trading and Strategic Incentives to Subsidize Green Energy, June 2010

3084 Henri Fraisse, Labour Disputes and the Game of Legal Representation, June 2010

3085 Andrzej Baniak and Peter Grajzl, Interjurisdictional Linkages and the Scope for Interventionist Legal Harmonization, June 2010

3086 Oliver Falck and Ludger Woessmann, School Competition and Students' Entrepreneurial Intentions: International Evidence Using Historical Catholic Roots of Private Schooling, June 2010

3087 Bernd Hayo and Stefan Voigt, Determinants of Constitutional Change: Why do Countries Change their Form of Government?, June 2010

3088 Momi Dahan and Michel Strawczynski, Fiscal Rules and Composition Bias in OECD Countries, June 2010

3089 Marcel Fratzscher and Julien Reynaud, IMF Surveillance and Financial Markets - A Political Economy Analysis, June 2010

3090 Michel Beine, Elisabetta Lodigiani and Robert Vermeulen, Remittances and Financial Openness, June 2010 
3091 Sebastian Kube and Christian Traxler, The Interaction of Legal and Social Norm Enforcement, June 2010

3092 Volker Grossmann, Thomas M. Steger and Timo Trimborn, Quantifying Optimal Growth Policy, June 2010

3093 Huw David Dixon, A Unified Framework for Using Micro-Data to Compare Dynamic Wage and Price Setting Models, June 2010

3094 Helmuth Cremer, Firouz Gahvari and Pierre Pestieau, Accidental Bequests: A Curse for the Rich and a Boon for the Poor, June 2010

3095 Frank Lichtenberg, The Contribution of Pharmaceutical Innovation to Longevity Growth in Germany and France, June 2010

3096 Simon P. Anderson, Øystein Foros and Hans Jarle Kind, Hotelling Competition with Multi-Purchasing: Time Magazine, Newsweek, or both?, June 2010

3097 Assar Lindbeck and Mats Persson, A Continuous Theory of Income Insurance, June 2010

3098 Thomas Moutos and Christos Tsitsikas, Whither Public Interest: The Case of Greece's Public Finance, June 2010

3099 Thomas Eichner and Thorsten Upmann, Labor Markets and Capital Tax Competition, June 2010

3100 Massimo Bordignon and Santino Piazza, Who do you Blame in Local Finance? An Analysis of Municipal Financing in Italy, June 2010

3101 Kyriakos C. Neanidis, Financial Dollarization and European Union Membership, June 2010

3102 Maela Giofré, Investor Protection and Foreign Stakeholders, June 2010

3103 Andrea F. Presbitero and Alberto Zazzaro, Competition and Relationship Lending: Friends or Foes?, June 2010

3104 Dan Anderberg and Yu Zhu, The Effect of Education on Martial Status and Partner Characteristics: Evidence from the UK, June 2010

3105 Hendrik Jürges, Eberhard Kruk and Steffen Reinhold, The Effect of Compulsory Schooling on Health - Evidence from Biomarkers, June 2010

3106 Alessandro Gambini and Alberto Zazzaro, Long-Lasting Bank Relationships and Growth of Firms, June 2010

3107 Jenny E. Ligthart and Gerard C. van der Meijden, Coordinated Tax-Tariff Reforms, Informality, and Welfare Distribution, June 2010 
3108 Vilen Lipatov and Alfons Weichenrieder, Optimal Income Taxation with Tax Competition, June 2010

3109 Malte Mosel, Competition, Imitation, and R\&D Productivity in a Growth Model with Sector-Specific Patent Protection, June 2010

3110 Balázs Égert, Catching-up and Inflation in Europe: Balassa-Samuelson, Engel's Law and other Culprits, June 2010

3111 Johannes Metzler and Ludger Woessmann, The Impact of Teacher Subject Knowledge on Student Achievement: Evidence from Within-Teacher Within-Student Variation, June 2010

3112 Leif Danziger, Uniform and Nonuniform Staggering of Wage Contracts, July 2010

3113 Wolfgang Buchholz and Wolfgang Peters, Equity as a Prerequisite for Stable Cooperation in a Public-Good Economy - The Core Revisited, July 2010

3114 Panu Poutvaara and Olli Ropponen, School Shootings and Student Performance, July 2010

3115 John Beirne, Guglielmo Maria Caporale and Nicola Spagnolo, Liquidity Risk, Credit Risk and the Overnight Interest Rate Spread: A Stochastic Volatility Modelling Approach, July 2010

3116 M. Hashem Pesaran, Predictability of Asset Returns and the Efficient Market Hypothesis, July 2010

3117 Dorothee Crayen, Christa Hainz and Christiane Ströh de Martínez, Remittances, Banking Status and the Usage of Insurance Schemes, July 2010

3118 Eric O'N. Fisher, Heckscher-Ohlin Theory when Countries have Different Technologies, July 2010

3119 Huw Dixon and Hervé Le Bihan, Generalized Taylor and Generalized Calvo Price and Wage-Setting: Micro Evidence with Macro Implications, July 2010

3120 Laszlo Goerke and Markus Pannenberg, 'Take it or Go to Court' - The Impact of Sec. 1a of the German Protection against Dismissal Act on Severance Payments -, July 2010

3121 Robert S. Chirinko and Daniel J. Wilson, Can Lower Tax Rates be Bought? Business Rent-Seeking and Tax Competition among U.S. States, July 2010

3122 Douglas Gollin and Christian Zimmermann, Global Climate Change and the Resurgence of Tropical Disease: An Economic Approach, July 2010

3123 Francesco Daveri and Maria Laura Parisi, Experience, Innovation and Productivity Empirical Evidence from Italy's Slowdown, July 2010 
3124 Carlo V. Fiorio and Massimo Florio, A Fair Price for Energy? Ownership versus Market Opening in the EU15, July 2010

3125 Frederick van der Ploeg, Natural Resources: Curse or Blessing?, July 2010

3126 Kaisa Kotakorpi and Panu Poutvaara, Pay for Politicians and Candidate Selection: An Empirical Analysis, July 2010

3127 Jun-ichi Itaya, Makoto Okamura and Chikara Yamaguchi, Partial Tax Coordination in a Repeated Game Setting, July 2010

3128 Volker Meier and Helmut Rainer, On the Optimality of Joint Taxation for NonCooperative Couples, July 2010

3129 Ryan Oprea, Keith Henwood and Daniel Friedman, Separating the Hawks from the Doves: Evidence from Continuous Time Laboratory Games, July 2010

3130 Mari Rege and Ingeborg F. Solli, The Impact of Paternity Leave on Long-term Father Involvement, July 2010

3131 Olaf Posch, Risk Premia in General Equilibrium, July 2010

3132 John Komlos and Marek Brabec, The Trend of BMI Values by Centiles of US Adults, Birth Cohorts 1882-1986, July 2010

3133 Emin Karagözoğlu and Arno Riedl, Information, Uncertainty, and Subjective Entitlements in Bargaining, July 2010

3134 John Boyd, Gianni De Nicolò and Elena Loukoianova, Banking Crises and Crisis Dating: Theory and Evidence, July 2010

3135 Michael R. Baye, Dan Kovenock and Casper G. de Vries, The Herodotus Paradox, July 2010

3136 Martin Kolmar and Hendrik Rommeswinkel, Group Contests with Complementarities in Efforts, July 2010

3137 Carolina Manzano and Xavier Vives, Public and Private Learning from Prices, Strategic Substitutability and Complementarity, and Equilibrium Multiplicity, July 2010

3138 Axel Löffler, Gunther Schnabl and Franziska Schobert, Inflation Targeting by Debtor Central Banks in Emerging Market Economies, July 2010

$3139 \mathrm{Yu}-\mathrm{Fu}$ Chen and Michael Funke, Global Warming and Extreme Events: Rethinking the Timing and Intensity of Environmental Policy, July 2010 